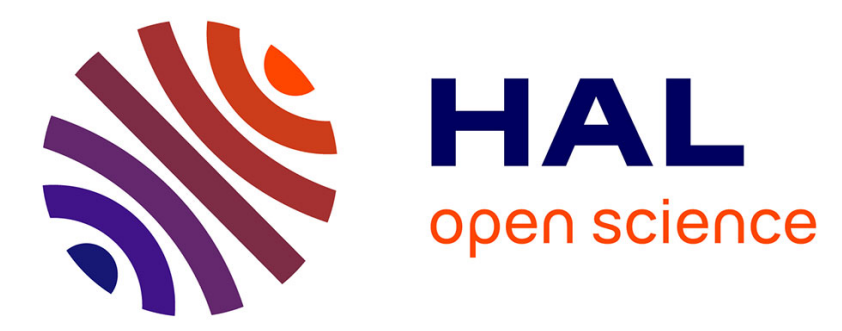

\title{
Combining experiments and modeling to explore the solid solution strengthening of high and medium entropy alloys
}

G. Bracq, M. Laurent-Brocq, C. Varvenne, L. Perrière, W.A. Curtin, J.-M. Joubert, I. Guillot

\section{To cite this version:}

G. Bracq, M. Laurent-Brocq, C. Varvenne, L. Perrière, W.A. Curtin, et al.. Combining experiments and modeling to explore the solid solution strengthening of high and medium entropy alloys. Acta Materialia, 2019, 177, pp.266-279. 10.1016/j.actamat.2019.06.050 . hal-02278482

\section{HAL Id: hal-02278482 \\ https://hal.science/hal-02278482}

Submitted on 29 Jan 2020

HAL is a multi-disciplinary open access archive for the deposit and dissemination of scientific research documents, whether they are published or not. The documents may come from teaching and research institutions in France or abroad, or from public or private research centers.
L'archive ouverte pluridisciplinaire HAL, est destinée au dépôt et à la diffusion de documents scientifiques de niveau recherche, publiés ou non, émanant des établissements d'enseignement et de recherche français ou étrangers, des laboratoires publics ou privés. 


\title{
Combining experiments and modelling to explore the solid solution strengthening of high and medium entropy alloys
}

\author{
G. Bracq ${ }^{1}$, M. Laurent-Brocq ${ }^{1,}{ }^{*}$, C. Varvenne ${ }^{2}$, L. Perrière ${ }^{1}$, W. A. Curtin ${ }^{3}$, J.-M. \\ Joubert ${ }^{1}$, I. Guillot ${ }^{1}$
}

\author{
${ }^{1}$ Université Paris Est, ICMPE (UMR 7182), CNRS, UPEC, F- 94320 THIAIS France \\ ${ }^{2}$ CINaM, UMR 7325, Aix-Marseille Univ., CNRS, F-13288, Marseille, France \\ ${ }^{3}$ Laboratory for Multiscale Materials Modeling, Institute of Mechanical Engineering, Ecole Polytechnique \\ Fédérale de Lausanne, Lausanne CH-1015, Switzerland
}

\section{Corresponding author}

First name: Mathilde ; Family name: Laurent-Brocq

E-mail: laurent-brocq@icmpe.cnrs.fr

Phone number : +33 (0)1 56703065

Postal adress : 2-8, rue Henri Dunant (bât D) F-94320 Thiais, France

\begin{abstract}
The mechanical properties due to solid solution strengthening are explored within the single phase fcc domain of the Co-Cr-Fe-Mn-Ni high entropy alloy (HEA) system. This is achieved by combining an efficient and reproducible metallurgical processing of alloys to $\mathrm{X}$-ray diffraction and nanoindentation characterization techniques, thus enabling to get access to 24 different bulk alloys. Large variations of nanohardness are seen with composition. Experimental results are rationalized in terms of lattice misfit and elastic constant variations with alloy-composition, through the use of an analytical mechanistic theory for the temperature-, composition- and strain-rate-dependence of the initial yield strength of fcc HEAs, with predictions made using only experimental inputs. The good agreement obtained by comparing model predictions to experiments provides the basic framework for mechanical properties optimization within the Co-Cr-Fe-Mn-Ni system; the approach could be systematically applied to all classes of fcc HEAs.
\end{abstract}

\section{Keywords}

Solute strengthening, metals and alloys, high entropy alloys, nanoindentation, analytical modelling 


\section{Introduction}

For a long time, metallic alloys were designed by choosing a main element to achieve primary property requirements, such as cost, weight or formability, and then by adding minor elements to improve the secondary properties, e.g. the mechanical ones. This conventional design strategy focuses on the apexes and edges of phase diagrams and thus is very restrictive in terms of possible chemical compositions. In 2004, Cantor et al. [1] proposed a new strategy, whose objective was to investigate the vast and unexplored central region of multi-component composition space, with the hope of finding unprecedented properties. This approach became successful with the discovery of an unusual multi-component alloy: the single phase equiatomic quinary CoCrFeMnNi alloy, also called the Cantor alloy, having a face centered cubic (fcc) structure [2]. Alloys such as the Cantor alloy, which are multi-component, single-phase and with high elemental concentrations - or in other words in which the distinction between main and minor elements has no sense anymore - were named high entropy alloys (HEAs) [3]. This stems from the fact that when the number of components increases and when the composition gets closer to equiatomic, the configurational entropy of an ideal solid solution increases. It was expected that such concentrated solid solutions would combine a high mechanical strength, due to an enhanced solid solution strengthening (SSS), and a high ductility, due to the homogeneous microstructure (i.e. the absence of precipitate interfaces or fragile secondary phases). Indeed, the quinary CoCrFeMnNi alloy exhibits high yield and ultimate tensile stress, together with a high rupture elongation and toughness [4-6]. Consequently, HEAs raised a great interest.

Since then, various works intended to find new alloys within the Co-Cr-Fe-Mn-Ni class forming single phase fcc solid-solutions. New interesting compositions were identified and mechanically tested, some of them having mechanical properties equivalent (e.g. $\mathrm{Cr}_{18} \mathrm{Ni}_{14} \mathrm{Fe}_{40} \mathrm{Mn}_{28}$ [7], $\mathrm{Cr}_{18} \mathrm{FeMnNi}$ [8] or $\mathrm{CO}_{5} \mathrm{Cr}_{2} \mathrm{Fe}_{40} \mathrm{Mn}_{27} \mathrm{Ni}_{26}$ [9]) or superior (CoCrNi $[10,11])$ to the Cantor alloy, or sometimes lower like $\mathrm{Co}_{6} \mathrm{Cr}_{2} \mathrm{Fe}_{26} \mathrm{Mn}_{38} \mathrm{Ni}_{28}$ [12]. These studies, while focusing on a few very specific compositions, motivate a more comprehensive exploration of the vast composition space of this multi-component system. In line with this, the stable phases of the quinary Co-Cr-Fe-Mn-Ni alloy system were entirely mapped at high temperature using a combination of experiments and Calphad calculations [13], showing a vast stability domain of single phase fcc solid solutions. Extending this work to map out and rationalize the bulk mechanical properties over this whole stability domain would be highly desirable, but faces important difficulties from an experimental perspective. Indeed, the composition domain to explore is large: an efficient, reliable and highly reproducible fabrication method is required for making a large number of bulk alloys. In addition, the mechanical properties of alloys are usually due to several strengthening mechanisms, e.g. SSS or Hall-Petch effect, that are necessary - but not straightforward - to separate in order to properly compare alloys having different compositions.

In this context, the objective of this study is both to explore the mechanical properties due to solute strengthening within the stability domain of the fcc solid solution in the Co-Cr-Fe-Mn-Ni system, and to provide physical understanding of their evolution with alloy composition. This is an important step toward optimization of the SSS with respect to alloy composition, and the recently developed HEAs, which are additionally strengthened by precipitates [14-16], should also benefit from this improved description of multi-component solid solutions. Our approach consists in (i) selecting specific lines (five isopleths) in the compositional space to cover as much as possible the quinary system, (ii) processing and characterizing the structure and SSS for a large number of bulk alloys within these lines, and (iii) connecting to the physical quantities dictating the trends of SSS with composition through the use of a recently developed model for SSS in HEAs [17]. To do so, a simplified and reproducible metallurgical process, which excludes time consuming thermomechanical treatments, was used. Then, lattice parameters were measured by X-ray diffraction and nanoindentation was selected as an efficient tool to measure only the SSS effect for these samples. Finally, model predictions were performed using as inputs only experimental data, including the lattice parameters measured here. 
The paper is organized as follows. Section 2 describes the experimental methods for alloy preparation and the characterization techniques used in this study, and recall the main elements of the solute strengthening model for random alloys. In Section 3, the experimental results are presented. In section 4, the computation of model inputs is detailed and model predictions are performed for the set of fabricated alloys. The evolution of predicted strengths with alloy composition is then compared to nanohardness values, and the article ends with a general discussion about experimental strategies for screening solute strengthening effect over a large compositional space.

\section{Methods}

\subsection{Materials and experimental methods}

All the investigated alloys have a composition based on the form $(A B C D)_{100-x} E_{x}$ where $A, B, C$ and $D$ are the elements in equiatomic proportion, $\mathrm{E}$ is the element whose content is made varying and $\mathrm{x}$ is in at. \%. They are named Ex. For example, the composition $\mathrm{Co}_{10} \mathrm{Cr}_{22.5} \mathrm{Fe}_{22.5} \mathrm{Mn}_{22.5} \mathrm{Ni}_{22.5}$ is named Co10. The only exception is the quinary equimolar alloy which belongs to the five isopleths and which is named CoCrFeMnNi. The name and nominal compositions of all the alloys are given in Table 1 . Only 3 compositions were selected on the $\mathrm{Ni}$ isopleth which was already studied in a previous work $[18,19]$.

All alloys were prepared with the same procedure, which is described in more details in [13]. Co, $\mathrm{Cr}, \mathrm{Fe}, \mathrm{Mn}$ and Ni metals, with a purity exceeding $99.9 \mathrm{wt} \%$, were melted by high frequency induction melting under a He atmosphere. Then gravity casting was used to shape the ingots into a rod with a diameter of $13 \mathrm{~mm}$ and a length of around $80 \mathrm{~mm}$. The rods were cut into slices of around 2-3 mm of length. Finally, those slices were wrapped into tantalum sheets, placed inside a sealed silica tube filled with $\mathrm{Ar}$ and annealed at $1373 \mathrm{~K}$ for 6 days. At the end of the annealing, the samples were quickly cooled down. As demonstrated in [13], this last processing step ensures that the studied alloys represent the high temperature (i.e. $1373 \mathrm{~K}$ ) stable state. Samples were prepared by mechanical grinding using 1200 to 4000 grit SiC papers, followed by a final polishing step using a vibratory table and a $0.04 \mu \mathrm{m}$ colloidal silica for a minimum duration of $15 \mathrm{~h}$.

The samples were characterized by X-ray diffraction (XRD) with a PANalytical XPert Pro diffractometer using the Co-K $\alpha$ radiation, at a wavelength of $0.178897 \mathrm{~nm}$ and an angular step of $0.016^{\circ}$. X-ray diffractograms were refined by the Rietveld method (FullProf software) and used to determine the lattice parameters [20]. The relative uncertainties which are due to data acquisition conditions and Rietveld refinement are respectively of 0.02 and $0.015 \%$. The uncertainty due to the metallurgical state of the sample was also assessed, focusing on the compositions $\mathrm{Co}_{20} \mathrm{Cr}_{20} \mathrm{Fe}_{20} \mathrm{Mn}_{20} \mathrm{Ni}_{20}, \mathrm{Co}_{10} \mathrm{Cr}_{10} \mathrm{Fe}_{10} \mathrm{Mn}_{10} \mathrm{Ni}_{60}$ and $\mathrm{Co}_{2} \mathrm{Cr}_{2} \mathrm{Fe}_{2} \mathrm{Mn}_{2} \mathrm{Ni}_{92}$. To do so, the lattice parameter was measured by XRD in the as-cast state (i.e. after gravity casting), in the homogenized state (i.e. samples of this study) and in the recrystallized state (i.e. : after cold-rolling and annealing at $1073 \mathrm{~K}$ for $1 \mathrm{~h}$, those samples are presented in [21]). The relative standard deviation on the lattice parameter for the three metallurgical states of one composition is of $0.05 \%$. This deviation is very likely due to differences in the size and shape of grains from one metallurgical state to another. In the following, the given uncertainty on lattice parameter is of $0.05 \%$ and corresponds to the uncertainty induced by the metallurgical state.

The samples were also characterized using a Zeiss Merlin Field Emission Gun Scanning Electron Microscope (FEG-SEM) with a BackScattered Electron (BSE) dectector and coupled with an Energy Dispersive X-ray Spectrometer (EDS) from Oxford Instruments. For single-phase samples, elemental mappings with a size of $110 * 80 \mu \mathrm{m}^{2}$ and $500 * 350 \mu \mathrm{m}^{2}$ were performed respectively to ensure the chemical homogeneity and to measure the average chemical composition. For two-phase samples, at least 10 point measurements were performed within the fcc phase to determine the average composition. The standard deviation on the different spectra from mapping or point measurements is between 0.1 and 0.4 at. \%. These samples were also mapped by Electron BackScattered Diffraction (EBSD), using the Oxford Instruments detector. A step size 
and a map width varying respectively from 50 to $600 \mathrm{~nm}$ and from 60 to $500 \mu \mathrm{m}$ were chosen, depending on the microstructure characteristic length. The volume fraction of the fcc phase was calculated from one EBSD map for each sample.

Mechanical characterization was performed by nanoindentation, using a TI950 Hysitron indenter, which was equipped with a Berkovich diamond tip. The surface topography was studied on surfaces of $10 * 10 \mu \mathrm{m}^{2}$ by Scanning Probe Microscopy (SPM), which consists in scanning the sample surface with the nanoindenter tip. A tilt smaller than $1^{\circ}$ and an arithmetic roughness between 2 and $8 \mathrm{~nm}$ were measured for all samples. Thus indents with a depth larger than $350 \mathrm{~nm}$, as considered here, are not influenced by the surface quality of the sample [22]. Each indentation was performed with a constant strain rate loading of $\dot{h} / h=0.05 s^{-1}$, where $h$ is the indentation depth. In other words, the loading rate increases exponentially with increasing time. The load was increased up to $12 \mathrm{mN}$, maintained during $5 \mathrm{~s}$ and unloaded for $5 \mathrm{~s}$ at a constant loading rate. The continuous stiffness measurement (CSM) was set up at a frequency of $200 \mathrm{~Hz}$, with an amplitude between 1 and $2 \mathrm{~nm}$ (Fig. 1d). For single-phase samples, ten positions were randomly chosen on a sample and at each position, a group of ten indents was performed. In total, one hundred indents were performed on each sample (Fig. 1a and b). With this procedure, different grains and crystalline orientations are tested. Indents were spaced by $10 \mu \mathrm{m}$ from each other, which represents more than 3 times the size of the final imprint and which thus ensures that there is no interaction between the strain field of indents. For the multi-phase sample $\mathrm{CoO}$, the fcc phase was not optically distinguishable from the second phase. So an area was identified by micro-indents, then it was mapped by EBSD and the groups of indents were placed within the fcc phase accordingly. In total, 84 indents were taken into account.

(a) Cylindrical sample

(b) Grains

(c) Nanoindentation print

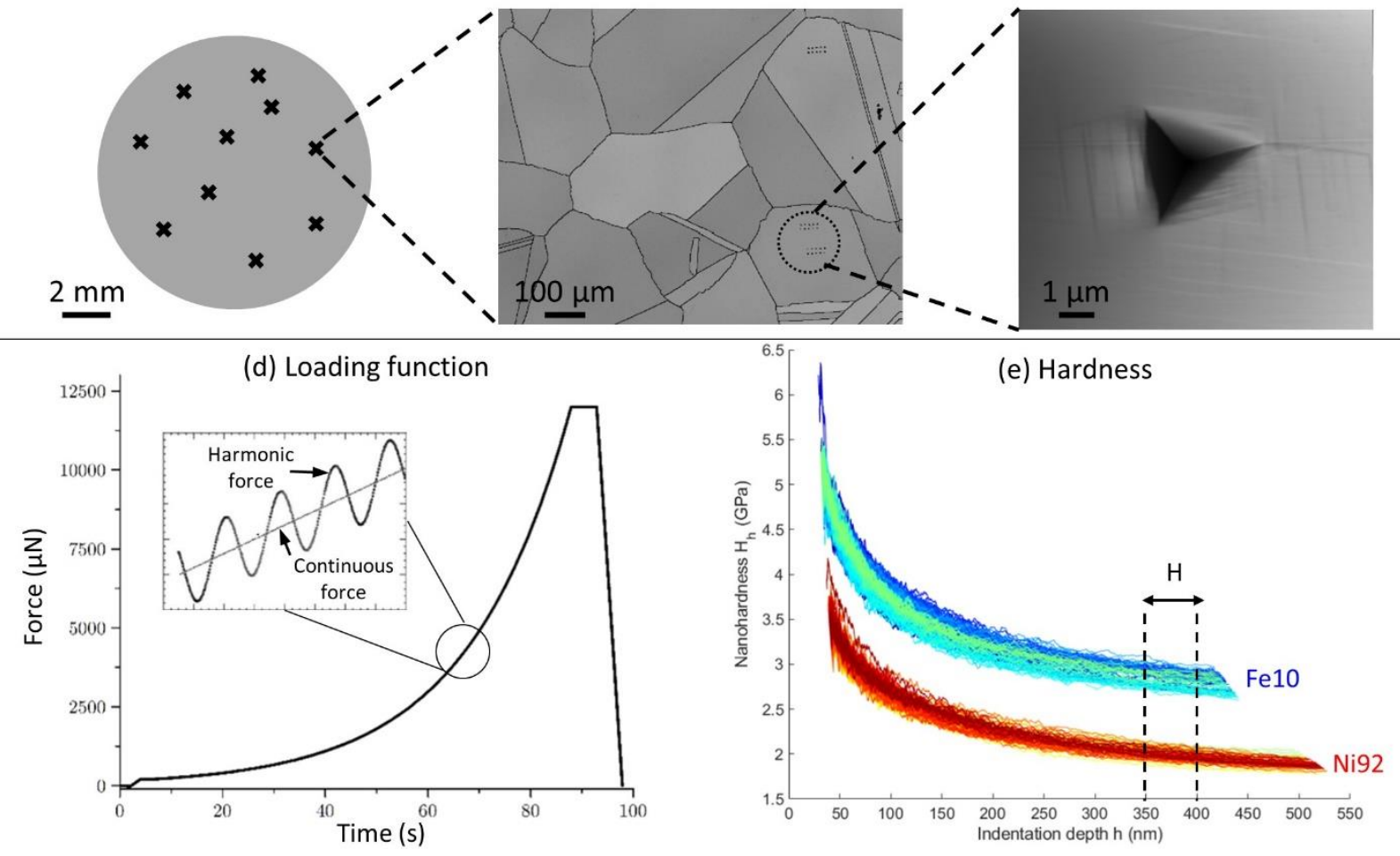

Fig. 1 : Presentation of nanoindentation measurements. (a) Scheme of the cylindrical shape of the samples and of the randomly distributed positions (black cross). (b) EBSD mapping (band contrast and grain boundaries). Three groups of ten indents can be seen. (c) Topography image of a nanoindentation indent obtained by SPM. (d) Nanoindentation loading function which was used for each indent. (e) Evolution of the nanohardness $\mathrm{H}(\mathrm{h})$ with indentation depth $h$. The one hundred curves obtained for two alloys (Fe10 and Ni92) are plotted. The range of averaging of $H(h)$ is indicated with a black arrow.

Continuous stiffness measurement was used to calculate reduced elastic modulus $\mathrm{E}_{\mathrm{r}}$ and hardness $\mathrm{H}$ versus indentation depth by the Oliver and Pharr method $[23,24] . \mathrm{E}_{\mathrm{r}}$ and $\mathrm{H}$ were averaged for indentation depth between 350 and $400 \mathrm{~nm}$ and on the one hundred indents performed on each sample (Fig. 1e). Large indentation depths were chosen to limit the indentation size effect [25]. It is mentioned that increasing or 
decreasing the averaging range of indentation depth of few tens of nanometers has no influence on the result. The given uncertainty corresponds to the standard deviation of the values from the one hundred indents. It is mentioned that the standard deviation on the averaged value for each group of ten indents was also calculated and is equivalent to the previous one.

Finally, a basic magnetism test was performed. All samples were placed close to a strong magnet at ambient temperature. They were identified as ferromagnetic if they were attracted by the magnet and paramagnetic otherwise.

\subsection{Solute strengthening modeling}

A general model for solution strengthening of random FCC alloys of arbitrary compositions, thus including HEAs, has been developed recently and is detailed in [17]. Given its success in predicting the yield strength of the CoCrFeMnNi HEA and of various of its equiatomic subsets, this model was chosen for this work. It describes each elemental component as a "solute" embedded into an effective "solvent" having all the average properties of the alloy, i.e. the model considers the substitutional atoms as local fluctuations in composition with respect to an effective-medium reference matrix. The strengthening then arises from the interaction of these chemical fluctuations with a dislocation, which adopts a wavy configuration characterized by a wavelength $2 \zeta_{c}$ and amplitude $w_{c}$ - to find energetically-favorable regions, but at the cost of an elastic energy due to the dislocation line tension $\Gamma$. The characteristic bow-out $\left(\zeta_{c}, w_{c}\right)$ describing the pinned dislocation is thus a compromise between these two energetic contributions. To unpin, the dislocation must escape from this local energy well, through a thermally activated process assisted by an applied resolved shear stress. The theory provides expressions for zero-temperature flow stress $\tau_{y 0}$ and activation energy barrier $\Delta E_{b}$ for the dislocation motion, with the solute/dislocation interactions, the line tension $\Gamma$ and the Burgers vector $b$ as inputs.

When using the elasticity size misfit contribution [26] to describe the interaction of "solutes" with the dislocation (misfit volume interaction), and rescaling the line tension as $\Gamma=\alpha \mu b^{2}$ with $\alpha=0.123$ as obtained from atomistic simulations [17], $\tau_{y 0}$ and $\Delta E_{b}$ are given by

$$
\begin{gathered}
\tau_{y 0}=0.051 \alpha^{-1 / 3} \cdot \bar{\mu}\left(\frac{1+\bar{v}}{1-\bar{v}}\right)^{4 / 3} \cdot f_{\tau}\left(w_{c}\right) \cdot\left[\frac{\sum_{n} c_{n} \cdot \Delta V_{n}^{2}}{b^{6}}\right]^{2 / 3} \\
\Delta E_{b}=0.274 \alpha^{1 / 3} \cdot \bar{\mu} b^{3}\left(\frac{1+\bar{v}}{1-\bar{v}}\right)^{2 / 3} \cdot f_{\Delta E}\left(w_{c}\right) \cdot\left[\frac{\sum_{n} c_{n} \cdot \Delta V_{n}^{2}}{b^{6}}\right]^{1 / 3}
\end{gathered}
$$

where $f_{\tau}\left(w_{c}\right)$ and $f_{\Delta E}\left(w_{c}\right)$ are dimensionless numerical coefficients associated with the dislocation core structure. The values 0.35 and 5.7 , respectively, covers a wide range of core structures with separation distances above $\approx 10 b$, and are thus typical for HEAs [27]. $n$ labels the alloy element at the overall composition $c_{n}$, and $\Delta V_{n}$ is the misfit volume of the $n$ species within the effective matrix. $\bar{\mu}$ and $\bar{v}$ are respectively the shear modulus and Poisson's ratio of the alloy.

At finite temperature $T$ and finite strain-rate $\dot{\varepsilon}, \tau_{y 0}$ and $\Delta E_{b}$ combine as

$$
\tau_{y}(T, \dot{\varepsilon})=\tau_{y 0} \cdot\left(1-\left(\frac{k T}{\Delta E_{b}} \cdot \ln \frac{\dot{\varepsilon}_{0}}{\dot{\varepsilon}}\right)^{2 / 3}\right)
$$

With $\dot{\varepsilon}_{0}$ a reference strain-rate connected to the dislocation density, Burger vector $b$, typical slip distance and attempt frequency. We set $\dot{\varepsilon}_{0}=10^{4} \mathrm{~s}^{-1}$, consistently to previous work [17], and $\dot{\varepsilon}=10^{-3} \mathrm{~s}^{-1}$ as this is the most commonly used strain rate for HEA tensile tests $[4,5,21]$. It should be noted that results are weakly sensitive to the precise values. 
Finally, the uniaxial yield stress $\sigma_{y}$ for an equiaxed fcc polycrystal is obtained by multiplying the flow stress by the Taylor factor as

$$
\sigma_{y}(T, \dot{\varepsilon})=3.06 \cdot \tau_{y}(T, \dot{\varepsilon})
$$

So once identified all material inputs $\left(\bar{\mu}, \bar{v}, b, c_{n}, \Delta V_{n}\right)$, predictions can be performed at the experimental temperature of $300 \mathrm{~K}$. The details of the computation of model inputs for alloys in this work will be given in section 4.1.

\section{Results}

\subsection{Choice of alloy compositions and microstructural characterization}

As raised in the introduction, the compositions to be experimentally studied were chosen according to two main criteria. First, to identify the role of each element ( $\mathrm{Co}, \mathrm{Cr}, \mathrm{Fe}, \mathrm{Mn}$ and $\mathrm{Ni}$ ), the content of this element was varied, while remaining the four others in equiatomic proportions. In other words, all the chosen compositions belong to the five isopleths of the quinary system and follow the form $(A B C D)_{100-x} E_{x}$. Second, to cover as much as possible the composition space of fcc solid solutions and to be able to compare HEA with dilute solid solutions, they were selected on the whole domain of existence of the fcc solid solution of each isopleth. In a previous study [13], the phase diagrams at $1373 \mathrm{~K}$ along the isopleth sections were calculated by the Calphad method and validated experimentally. They were thus used here to select the compositions. As can be seen on Fig. 2a, the size of the fcc domain and accordingly the number of selected compositions vary on each isopleth. In total, 24 compositions were selected and are listed in Table 1.

The 3 alloys $\mathrm{CoO}, \mathrm{Cr} 42$ and $\mathrm{NiO}$ are not in the single fcc domain of the phase diagram (Fig. 2a). Indeed, $\mathrm{CoO}$ is composed of fcc and body centered cubic (bcc) phases, while $\mathrm{Cr} 42$ and NiO contain fcc and $\sigma$ phases (Fig. A $1 a, b, d$ and [13]). The interest of these alloys is that their fcc phases are on the limit of the fcc domain. The volume fraction of the fcc phase is $93.8,30.8$ and $65.5 \%$ (Table 1) for $\mathrm{CoO}, \mathrm{Cr} 42$ and NiO, respectively. The alloys Fe70, Co70 and Co90 are in the single-phase fcc domain at high temperature (Fig. 2a). However, on the EBSD mappings (Fig. A 1c and e) and SEM image (Fig. A 1f) of the processed alloys, a bcc phase for Fe70 and a Co $\varepsilon$ phase for Co70 as well as Co90 appear in addition to the fcc phase. As already laid out in [13] for Co90, the Co $\varepsilon$ phase is very likely due to a partial martensitic-like transformation. For Fe70, the isopleth phase diagram (Fig. 2a) indicates the formation of a bcc phase at intermediate temperatures (around $900 \mathrm{~K}$ ). It appears that the high temperature stable state of Fe70, Co70 and Co90 was not possible to completely stabilize during cooling. Still, the fcc phase can be, at least partially, studied.

Finally, the 18 remaining alloys are single fcc solid solutions as predicted by thermodynamic calculations (Fig. 2a). Indeed, for those 18 samples, all the peaks of the XRD pattern could be indexed by the fcc phase; no secondary phases nor chemical fluctuations were detected on SEM images or EDS mappings (results not shown here).

Fig. 3 displays an XRD pattern and an SEM image which are representative of those 18 samples. The grains have irregular shapes, and sizes larger than at least $200 \mu \mathrm{m}$, which is expected for homogenized and unrecrystallized samples.

The composition of the fcc phase is given in Table 1 for the 24 processed alloys. For the single-phase alloys, the average and maximum differences between the nominal and measured compositions are respectively 0.3 and 0.9 at. \%. This is a very good agreement. For the two-phase alloys, the composition of the fcc phase is equal or close to the nominal composition for respectively Co70, Co90 and CoO. On the contrary, for Cr42, $\mathrm{Fe} 70$ and $\mathrm{NiO}$, the composition of the fcc phase deviates from the nominal composition and thus those phases do not exactly belong to the isopleths of $\mathrm{Cr}$, Fe and $\mathrm{Ni}$ respectively. 


\subsection{Lattice parameter}

The lattice parameter of the fcc phase was measured by X-ray diffraction for all samples. The average atomic volume $\bar{V}_{\text {exp }}$ was computed according to the formula for fcc structure:

$$
\bar{V}_{\text {exp }}=\frac{a^{3}}{4}
$$

Where $a$ is the lattice parameter. $a$ and $\bar{V}_{\text {exp }}$ are given in Table 1. It is mentioned that the lattice parameter measured for CoCrFeMnNi and $\mathrm{MnO}$ are in quantitative agreement with $[2,28,29]$ and [30] respectively, while the ones of $\mathrm{Ni60}$ and Ni92 agree with [18]. $\bar{V}_{\text {exp }}$ is also plotted for each isopleth in Fig. $2 \mathrm{~b}$. It can be seen that the average atomic volume varies over a range of more than $1 \AA^{3}$, from $11.08 \AA^{3}$ for Ni92 to $12.10 \AA^{3}$ for Mn50. This is way larger than the measurement uncertainty of $0.02 \AA^{3}$. Consequently, the effect of each element on the average atomic volume can be studied.

On the isopleth of Co, Fe and $\mathrm{Mn}$, the evolution of $\bar{V}_{\text {exp }}$ is approximately linear. When the concentration of Co or Fe increases, $\bar{V}_{\text {exp }}$ decreases whereas $\bar{V}_{\text {exp }}$ increases with $\mathrm{Mn}$ content. For the $\mathrm{Cr}$ isopleth, when the $\mathrm{Cr}$ content increases from 0 to 20 at. $\%, \bar{V}_{\text {exp }}$ is constant and afterwards, it slightly increases. When the $\mathrm{Ni}$ content increases, $\bar{V}_{\text {exp }}$ continuously but non linearly decreases, as already reported in [19]. From 0 to around 50 at. $\%, \bar{V}_{\text {exp }}$ slowly decreases and for larger content, the decrease is more pronounced. Thus the tendency of evolution of the average atomic volume is isopleth-specific. Finally, it is underlined that $\mathrm{Mn}$ and Co induce the most important variation of $\bar{V}$ while $\mathrm{Cr}$ induces the smallest one.

Since magnetism can influence lattice parameter and since $\mathrm{Fe}, \mathrm{Ni}$ and $\mathrm{Co}$ are well-known ferromagnetic elements while $\mathrm{Cr}$ is antiferromagnetic, the magnetization of the processed alloys is now considered (Table 1). Most of the studied alloys are paramagnetic at ambient temperature. Fe70, Co70 and Co90 are ferromagnetic. However, since these alloys are two-phase, it cannot be determined whether the fcc phase or the other phase is ferromagnetic. Alloys from the $\mathrm{Ni}$ isopleth with a $\mathrm{Ni}$ content larger than 60 at. \% are ferromagnetic. This change of magnetic state appears for the same composition as an acceleration of the $\bar{V}_{\text {exp }}$ decrease. Thus the magnetization seems to influence the non-linear evolution of lattice parameter for the $\mathrm{Ni}$ isopleth. It is underlined that, for the $\mathrm{Cr}$ isopleth, there is no change of magnetization and still, the evolution of lattice parameter is not linear. To conclude more tightly, magnetic properties have to be investigated in more details.

\subsection{Nanohardness}

Nanoindentation was chosen to measure the mechanical properties of processed alloys because it permits to test samples of millimetric dimensions (Fig. 1a), contrary to tensile tests. Moreover, this technique being combined to the simplified metallurgical process used here, only the effect of SSS is measured. Indeed, first, since all the samples were homogenized in the same way by a high temperature and long duration annealing, the density of pre-existing dislocation can be considered to be low and similar in all samples. Thus, in a first approximation, the strengthening effect of pre-existing dislocations can be neglected. Second, the grain size is larger than at least $200 \mu \mathrm{m}$ while the indent depth and width are $400 \mathrm{~nm}$ and $3 \mu \mathrm{m}$ respectively (Fig. 1b and c), which induces a plastic zone with a diameter of around $12 \mu \mathrm{m}$ [31]. Thus it can be assumed that indents are always far away from a grain boundary as it is illustrated for 3 groups of indents on Fig. 1 b. Consequently grain boundary strengthening can also be neglected.

For single-phase processed alloys, the given hardness is the average of 100 indents which are distributed on 10 random positions on the sample (see 2.1 and Fig. 1a, b). A group of indents belongs to the same grain and each group is positioned on different grains which, most of the time, have different crystalline orientations. 
This large number of indents per sample is intended to provide a reliable averaging of properties, despite the local nature of nanoindentation. For two-phase alloys, the sizes of fcc domains and of the plastic zone which is induced by nanoindentation were compared to determine whether or not it was possible to measure the nanohardness of the fcc phase without any interaction of the second phase. The length of fcc domains are smaller than $0.5 \mu \mathrm{m}$ for Fe70, around $3 \mu \mathrm{m}$ for Co90 and around $10 \mu \mathrm{m}$ for $\mathrm{Cr} 42$ and Ni0, which is smaller than the plastic zone. For Co70, some domains have dimensions close to $50 \mu \mathrm{m}$. However, since the volume fraction of the fcc phase is only of $36 \%$, it is likely to have some interactions with domains of the second phase underneath the tested fcc area. Consequently, the hardness of the fcc phase was not possible to measure for Fe70, Co70, Co90, Cr42 and NiO. On the contrary, for CoO, the average size of fcc domain is 40 $\mu \mathrm{m}$ and the volume fraction of fcc is $94 \%$. Thus the hardness was measured by positioning indents selectively in the middle of fcc domains (as described in 2.1).

The measured hardness for each sample is given in Table 1 and plotted in Fig. 2c. First, it can be noticed that the hardness varies over a large range of $1.3 \mathrm{GPa}$. The composition has a very significant influence on the SSS in the Co-Cr-Fe-Mn-Ni system. More precisely, the alloys $\mathrm{Fe} 0$ and $\mathrm{Ni60}$ are the hardest, with hardness values of respectively 3.2 and $2.9 \mathrm{GPa}$ whereas Fe50 and Ni92 are the softest, with hardness values of respectively 1.9 and $2.0 \mathrm{GPa}$. The equimolar CoCrFeMnNi has an intermediate hardness value of $2.5 \mathrm{GPa}$. Thus the Cantor alloy is clearly not the composition which maximizes the SSS within the Co-Cr-Fe-Mn-Ni system, as noted earlier in the literature [19, 32]. Second, it can be seen that the trend of hardness along an isopleth differs according to the considered element. There is a plateau of hardness for compositions around CoCrFeMnNi for the $\mathrm{Co}, \mathrm{Cr}$ and $\mathrm{Mn}$ isopleths. In other words, the hardness only slightly varies with composition around the equimolar composition. Observing specifically the effect of each element, the hardness linearly decreases when the Fe content increases while it increases with Co content, with some deviations from linearity. For $\mathrm{Cr}, \mathrm{Mn}$ and $\mathrm{Ni}$, the hardness curve is bell-shaped: it first increases with each elemental content and decreases afterwards. For $\mathrm{Cr}$, the decreasing part is almost absent since the fcc solid solution is not stable for high $\mathrm{Cr}$ content. The amplitude of variations of hardness with $\mathrm{Mn}$ content is more limited as compared to $\mathrm{Ni}$. The maximum of hardness appears for content of $\mathrm{x}=15,10$ and 60 at. \% for respectively $\mathrm{Cr}, \mathrm{Mn}$ and $\mathrm{Ni}$. Several preliminary conclusions can already be drawn. First, a qualitative influence of the increase of each element on hardness can be proposed: (i) Fe is unfavorable, (ii) $\mathrm{Co}$ and $\mathrm{Cr}$ are favorable, (iii) $\mathrm{Mn}$ and even more Ni are favorable until a maximum content. However, it should be underlined that the effects of the various elements are correlated since the increase of one element induces the decrease of other elements. Thus, a more quantitative description is needed. Second, as observed for lattice parameter, the tendency of evolution of the average atomic volume is isopleth-specific. In a previous work on the Ni isopleth [19], the breakpoint of evolution of both the lattice parameter and the hardness at 60 at. \% of $\mathrm{Ni}$ was proposed as the transition between high entropy alloys and conventional diluted alloys. However, no such breakpoint is identified for the other isopleth sections. It must be specified that the range of composition of fcc solid solutions which were possible to study for $\mathrm{Co}, \mathrm{Fe}, \mathrm{Mn}$ and especially $\mathrm{Cr}$, is more limited than for $\mathrm{Ni}$, and does not include dilute fcc solid solutions. It seems that, as for other materials, the properties of multi-component alloys evolve continuously with composition, until a phase transition takes place. In other words, there is no real physical separation between high entropy alloys and diluted solid solutions.

In addition to the hardness, nanoindentation allows to determine a local elastic modulus. With our nanoindentation procedure on homogenized samples, as previously exposed, several crystalline orientations are individually tested. For the studied alloys, the measured elastic modulus significantly varies with the crystalline orientation. This reflects an important anisotropy of elastic constants, which was indeed calculated earlier from ab-initio in the case of the Cantor alloy [33]. The values obtained here on the ten grain orientations are not numerous enough to average the effect of anisotropy [21] and sufficiently reduce the uncertainty to get reliable trends of moduli with compositions. Consequently, the measured elastic moduli were not exploited. 


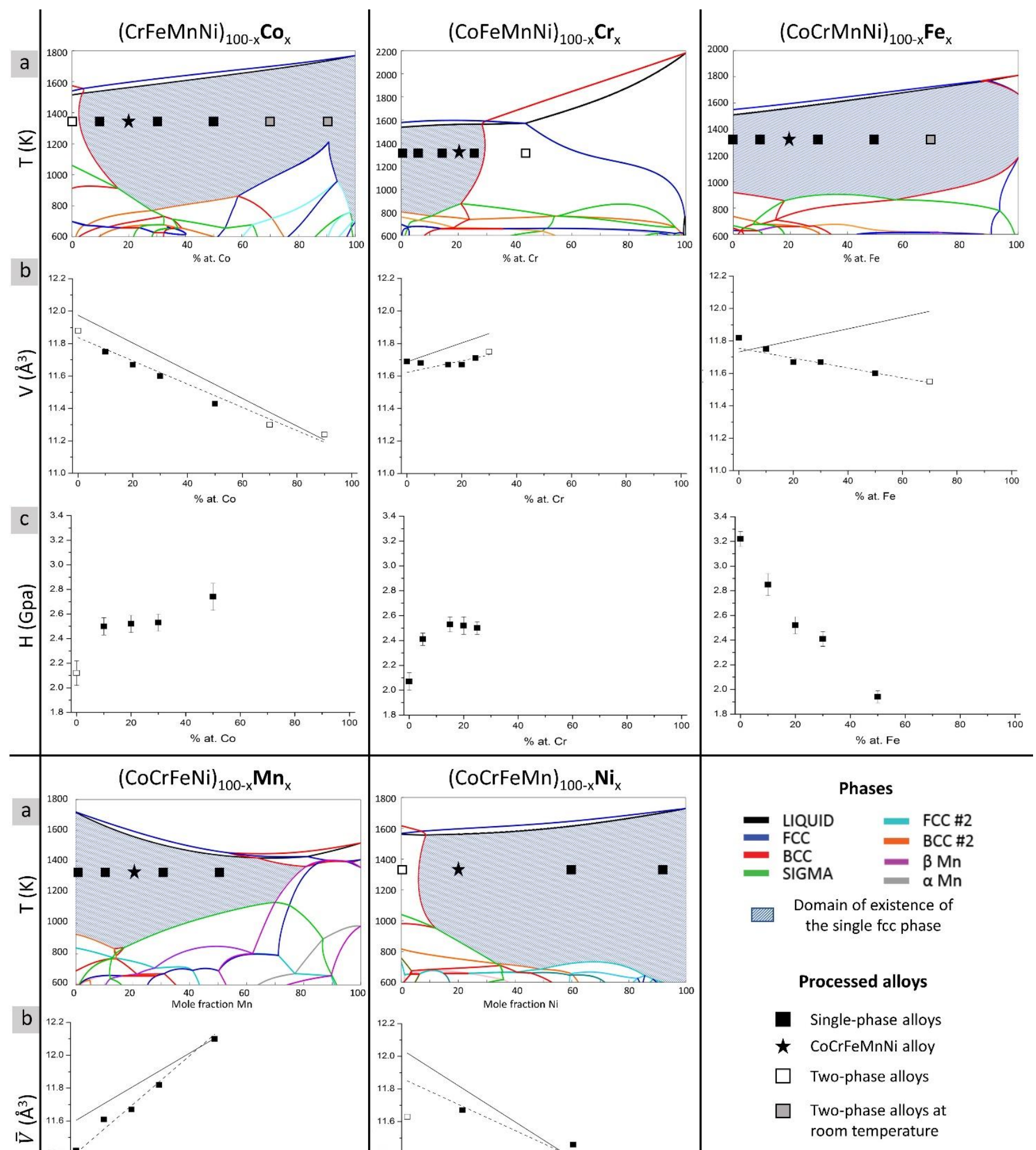

Alloy volume $\bar{V}_{\text {exp }}$ and hardness $\mathbf{H}$

$\mathrm{H}$ or $\mathrm{V}$ measured on a singlephase alloy

$\mathrm{H}$ or $\mathrm{V}$ measured in the fcc phase of a two-phase alloy

\section{Calculated alloy volume $\bar{V}$}

- - - Fitted on a dataset from this work Fitted on a dataset from Varvenne et al. [17] 
Fig. 2 : Calculated and experimental data for the 24 processed alloys. The graphs are organized in five columns corresponding to the five isopleths and in three lines (a), (b) and (c) which are described in the following. (a) Isopleth sections calculated with the Calphad method and the TCHEA-1 data base. The 24 processed alloys are indicated at the homogeneization temperature. (b) Experimental average alloy volumes $\bar{V}_{\text {exp }}$ measured by XRD and calculated average volumes $\bar{V}$ based on two datasets. The error bars for $\bar{V}_{\text {exp }}$ are smaller than the symbols (c) Hardness measured by nanoindentation. The erros bars are the standard deviation on all measurements on a given sample.
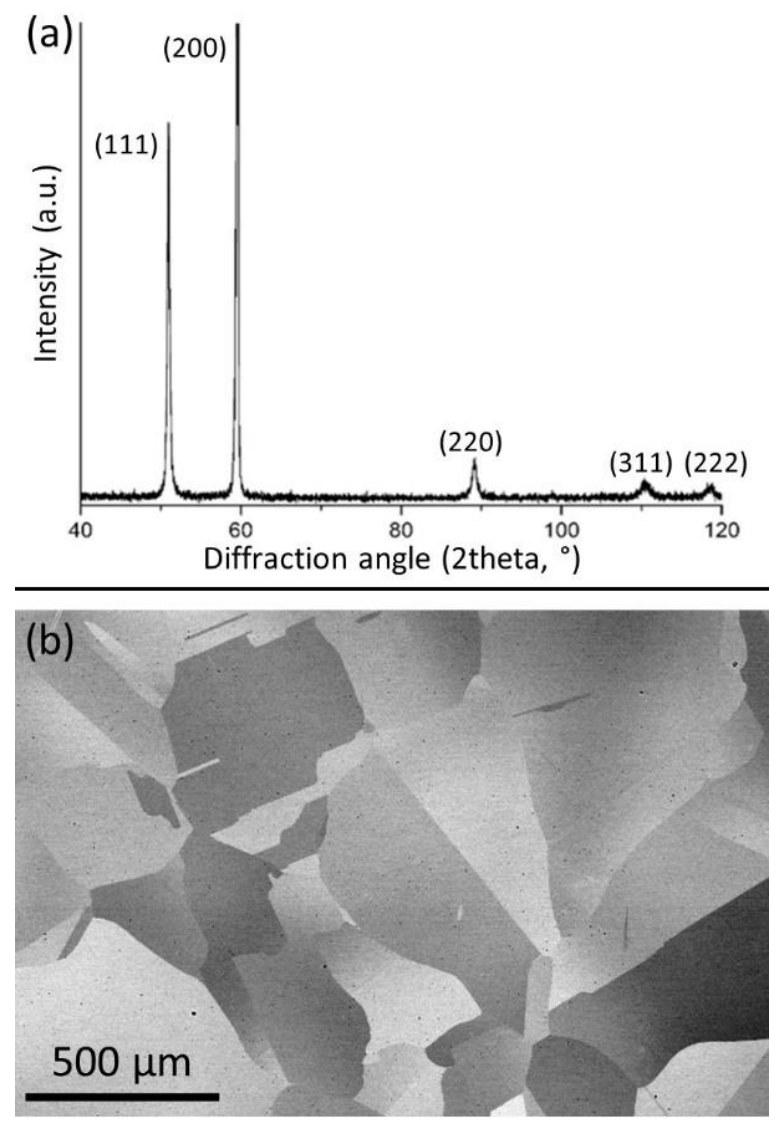

Fig. 3 : Microstructural characterization of single-phase alloy Fe10, which is representative of all single-phase samples. (a) XRD pattern. The crystallographic planes of the fcc solid solution are indicated. (b) BSE-SEM image showing grains.

\section{Discussion}

In this section, model predictions are performed using experimental data from this work and from the literature. Then, the predicted yield strengths are discussed regarding the experimental results of nanoindentation tests. In particular, the ability of nanoindentation to probe the solute strengthening contribution to the mechanical strength of HEAs and the effect of model inputs on the predicted strength values are examined. Finally, experimental strategies for exploring solid solution strengthening in HEAs are discussed more broadly.

\subsection{Computation of solute strengthening model inputs}

Making strength predictions requires the computation of the concentration-dependent values of the misfit volumes and elastic constants for the alloys of the five isopleths. Two additional approximations are made for this purpose.

For the alloy misfit volumes, a Vegard's law is applied as $\Delta V_{n}=V_{n}-\bar{V}$, where $V_{n}$ is the atomic volume of the $n$ species, and $\bar{V}=\sum c_{n} V_{n}$ is the alloy average atomic volume. The $V_{n}$ are obtained from a fitting of the average atomic volumes $\bar{V}$ from two different experimental datasets, consisting (i) of the five isopleth alloys 
in the present work, and (ii) of pure $\mathrm{Ni}$, various binary systems and a few equiatomic alloys from the Co- $\mathrm{Cr}$ Fe-Mn-Ni system as obtained in the work of Varvenne et al. [17]. Resulting $V_{n}$ values are given in Table 2. In general, the atomic volumes $\bar{V}$ of the alloys from the five isopleths are better reproduced by the first set of $V_{n}$ (Fig. 2b). However, the important quantity for SSS at a specific composition are the $\Delta V_{n}$ rather than the exact $\bar{V}$, and those quantities are connected to the local slope $\partial \bar{V} / \partial x$, where $x$ is the atomic content of the non-equimolar element (e.g.: $\mathrm{x}=\%$ at. of $\mathrm{Ni}$ on the $\mathrm{Ni}$ isopleth). Comparing the slopes with $\mathrm{x}$ for both adjustments, differences are less marked than for the $\bar{V}$ except for the Fe-isopleth. But for this last case, the impact on the predicted SSS is limited, as dsecribed in section 4.2.

For the alloy elastic constants, rule-of-mixtures are used, as $\bar{E}=\sum c_{n} E_{n}$ and $\bar{\mu}=\sum c_{n} \mu_{n}$, and the Poisson's ratio is recovered through the isotropic elasticity relation $\bar{v}=\bar{E} / 2 \bar{\mu}-1$. As the elastic moduli measured by nano-indentation could not be workable (section 3.3), we rely on already published experimental measurements of room-temperature elastic constants for the adjustment of the elemental $\left(\mu_{n}, E_{n}\right)$. Again, two datasets are considered, both involving equiatomic subsets of the CoCrFeMnNi alloy: the elastic constants from Laplanche et al. [34], and the elastic constants from Wu et al. [29], which are recalled in Table A1. The fitted elemental values are given in Table 2. Similar relative orders of elastic moduli can be seen in both adjustments, with Fe having the lowest and $\mathrm{Cr}$ the highest $\left(\mu_{n}, E_{n}\right)$ values. More specifically, differences of 9-15\% are seen for $\mu_{F e}, \mu_{M n}, \mu_{N i}, E_{C o}$, and $E_{F e}$, and values are very similar for the others, thus showing the sensitivity of the obtained elemental elastic moduli to the adjustment dataset.

\subsection{Solute strengthening model predictions}

Predictions for the room-temperature yield strength $\sigma_{y}\left(T=300 K, \dot{\epsilon}=10^{3} \cdot \mathrm{s}^{-1}\right)$ are calculated from Eqs (1) to (4), using the possible sets of atomic volumes $V_{n}$ and of elastic constants from Table 2 and with the experimental compositions from Table 1. For each studied alloy, the predicted $\sigma_{y}$ are given in Table A2. The yield strengths, rescaled by the CoCrFeMnNi yield strength, are plotted in Fig. 4(a) and (b), whose values correspond to the set of $V_{n}$ obtained respectively from this work and from Varvenne et al. [17]. The upper and lower bounds of the error bars cover results from adjustments on either Laplanche or Wu datasets of elastic constants, and the lines correspond to the arithmetic average between the two. For clarity, predictions are also shown isopleth by isopleth in Fig. 5. It is worth underlining that predictions for the CoCrFeMnNi alloy are similar whatever the adjustment of elemental atomic volume and elastic constants; consequently, comparing the ratios $\sigma_{y} / \sigma_{y}^{C O C r F e M n N i}$ for the different predictions makes sense.

As seen in Fig. 5, for both adjustments of the $V_{n}$, the trends of strength for $\mathrm{Co}, \mathrm{Cr}$ and $\mathrm{Fe}$ along the isopleth are similar. For the $\mathrm{Mn}$-isopleth, both strength curves are bell-shaped; but with the adjustment of Varvenne et al. [17], from $x=0$ to 0.1 a plateau is observed and for $x>0.1$ the strength decreases, whereas with the adjustment from this work, the strength strongly increases up to $x=0.3$ and then decreases. As a result, the relative order of the $\mathrm{Co} / \mathrm{Cr} / \mathrm{Mn}$ curves it not the same at small $x$, in Fig. 4 (a) and (b). Such differences arise from the different values of $V_{M n}$ obtained using different datasets (Table 2). Specifically, using the $\bar{V}$ of the present work, $V_{M n}$ is significantly larger than all other elemental atomic volumes, and in [17], $V_{M n}$ is rather close to $V_{C r}$ and $V_{F e}$. Finally, for the $\mathrm{Ni}$-isopleth, which has only three datapoints, the rescaled predicted strength is nearly equivalent for $x=0.2$ and $x=0.92$ with the two adjustments, but differs somewhat for $x=0.6$ : at this composition in Fig. 4 (b) the strength is the highest, and in Fig. 4 (a), the strength is intermediate. If one looks at the predictions of alloy atomic volumes with the two adjustments for the Ni-isopleth (Fig. 2b), one sees that none of them is really satisfactory for this isopleth. Actually, the evolution of $\bar{V}$ with the at. \% of $\mathrm{Ni}$ is not linear as already mentioned in this work (section 3.2) and in a previous work on more compositions [19]; thus a Vegard's law is not fully justified. The overall observed differences between the predictions in Fig. 4 (a) and (b) and within each subfigure of Fig.5, are a result of the sensitivity of the model to the misfit volume quantities, and to the difficulty of having a Vegard's law for the average atomic volume valid for the 
whole range of alloy composition, especially with elements that are magnetic and are known to induce deviations to linear behavior.

We now comment the effect of the two different datasets used for the identification of the alloy elastic constants. No significant differences are seen for the whole $\mathrm{Cr}$ and $\mathrm{Mn}$ curves, and for compositions close to the equiatomic CoCrFeMnNi alloy for the other isopleths. A greater uncertainty is observed for $x_{C_{0}}=0.3$, for $x_{\mathrm{N}} \geq 0.6$, and for $x_{\mathrm{Fe}}=0.1$ and 0.5. Again, imposing a linear behavior for the whole composition could be questioned, but here there is an intrinsic spreading in the datasets used to adjust the $\left(E_{n}, \mu_{n}\right)$ : the same alloys can have different isotropic elastic constants in [34] and [29] (see Table A1 for actual values). Therefore, measuring directly the elastic constants of the alloys of this study would be desirable to increase the precision of the predictions.

\subsection{Comparison to nanoindentation}

The predictions made can now be compared to the experimental results of nanohardness. The rescaled experimental hardness $\mathrm{H} / \mathrm{H}_{\text {CocremnNi }}$ is shown on Fig. 4 (c) and is also included into Fig. 5, with error bars defined in section 2.1. To assist in the physical understanding of the evolution of mechanical properties with composition, Table 3 provides the elastic constants $(\bar{\mu}, \bar{v})$ and the lattice misfit parameter $\delta=$ $\left(2 \sum c_{n} \Delta V_{n}^{2} / 9 b^{6}\right)^{1 / 2}$ [35] (related to the misfit volume term) for all studied alloys. Those quantities are important for the strength, as seen in Eqs. (1) and (2). The predicted evolution of strength with $x$ (both Fig. 4 (b) and (c)) agrees very well with the observed experimental trends for both Fe and Co. The strong decrease of strength with increasing $x_{\mathrm{Fe}}$ is assigned to an important decrease in elastic modulus, together with a decrease in lattice misfit $\delta$. The slightly increasing but essentially flat behavior for Co stems from a combination of very little variations of $\delta$ term and almost constant elastic moduli. For $\mathrm{Cr}$, both models predictions indicate a plateau for compositions around the equiatomic quinary alloy, as in experiments, due to a compensation between a decreasing $\delta$ and an increasing $\bar{\mu}$ with $x_{C r}$. The lower strength seen at $x_{\mathrm{Cr}}=0$ is predicted when using the $V_{n}$ from [17], even if not fully recovered. The $\mathrm{Mn}$-and $\mathrm{Ni}$-isopleth predictions using the $V_{n}$ from [17], show excellent agreement in trends and rescaled values with the experiments, contrary to the predictions using misfit volumes from this work, especially for $x_{\mathrm{Mn}} \leq 0.1$ and $x_{\mathrm{Ni}}=0.6$. This is in line with the sensitivity on the alloy atomic volume dataset used for the identification of the $V_{n}$ quantities, as noted previously. The evolution of strength with $x_{M n}$ is strongly influenced by $\delta$, as $\bar{\mu}$ is nearly constant over this composition range. The evolution of strength with $x_{N i}$ depends mainly on the evolution $\delta$ in combination with a slight decrease of $\bar{\mu}$. We finally note that the experimental hardness of the sample $x_{N i}=0.92$ is rather high, and that predictions are a factor of $\approx 2$ below due to a very small $\delta$ at this Ni-rich composition; this is further commented later on. The overall agreement with nanohardness trends is a bit better achieved by the predictions made with the $V_{n}$ from [17].

It is worth mentioning that the comparison between ratios of yield strength predictions and ratios of nanohardness measurements assumes (i) the same correlation - i.e. same proportionality factor - between experimental hardness and experimental yield strength for all studied alloys, and (ii) the ability of the model

to reproduce the true experimental strengths. If both points hold, then the quantity $\sigma_{y}^{\text {pred }} / H_{y}^{\text {exp }}$ should be constant (or nearly constant) across all alloys. In this case, the model is predictive. Otherwise, then either point (i) or (ii) is not fulfilled. Deviations from (i) arise from the fact that besides the complex stress field created by nanoindentation, it has to be taken into considerations that indentation induces a plastic strain of $7 \%$ for a Berkovich tip [36], whereas yield strength is determined at the onset of plasticity, usually at 0.2 $\%$ of plastic deformation. A difference is thus expected for alloys having different strain hardening. Moreover, in this work, homogenized samples are indented whereas recrystallized samples are usually used for tensile tests. This might induce a small remaining difference of pre-existing dislocations density and, as a consequence, of the forest hardening effect. It should be added that, since strain and forest hardening are 
influenced by composition, their effect may vary from alloy to alloy. On the other hand, the condition (ii) might be unfulfilled due to either a difficulty in obtaining accurately the model inputs, or a model assumption that is not adequate. This is examined for the studied alloys in the following.

Computation of the $\sigma_{y}^{\text {pred }} / H_{y}^{e x p}$ for all alloys (not shown here), using the different sets of atomic $\left(V_{n}, \mu_{n}, E_{n}\right)$, shows a constant value $\pm 15 \%$ for a large range of $x$ in the isopleths, justifying the above comparisons and physical comments. More important deviations are observed for $x_{\mathrm{Ni}} \geq 0.6, x_{\mathrm{Cr}}=0, x_{\mathrm{Fe}}=0.5$ and $x_{\mathrm{Mn}} \leq 0.1$ with the $V_{n}$ from this work, and for $x_{\mathrm{N}}=0.92, x_{F e}=0.5$ and $x_{\mathrm{Mn}}=0.5$ when using the $V_{n}$ of Varvenne et al.; these thus deserve more discussions. Assessment of the constant proportionality relation between experimental yield strength and experimental nanohardness (point (i)) was quantitatively investigated on HEAs from the $\mathrm{Ni}$ isopleth, which were tested both by nanoindentation and by tensile tests [21]. The rescaled experimental yield strengths $\sigma_{y} / \sigma_{y}$, ${ }^{C}$ CrFeMnNi were measured to be 1.0 and 0.6 for Ni60 and Ni92 respectively [21]. For Ni60, the experimental value is in between the predictions based on atomic volumes from [17] and the ones from this work (Fig. 5). For Ni92, the agreement with the predictions is better when compared with the yield strength than with the nanohardness (Fig. 5). More broadly, it was concluded that an additional error of $20 \%$ must be included to the experimental results, to account for the differences between the nanohardness measurement on homogenized samples and the yield strength (see Fig.5). Repeating tensile tests for other isopleth alloys would allow to refine further this error bar. Concerning point (ii), some sensitivity of the model predictions is indeed seen with respect to the chosen dataset to obtain the atomic $\left(V_{n}, \mu_{n}, E_{n}\right)$ : the set of $V_{n}$ influences the trend of strength mainly for $\mathrm{Mn}$ and $\mathrm{Ni}$-isopleths, and the set of $\left(\mu_{n}, E_{n}\right)$ influences the slope value in the Fe-isopleth, with consequences especially for the compositions most remote from the equimolar. This could be refined typically by going beyond the simple Vegard's approximation used here and by performing additional alloy elastic moduli measurements. In conclusion, within the higher experimental error bars on nanohardness, both model predictions achieve a similar and satisfactory level of agreement with the experimental results as can be seen on Fig. 5 . 

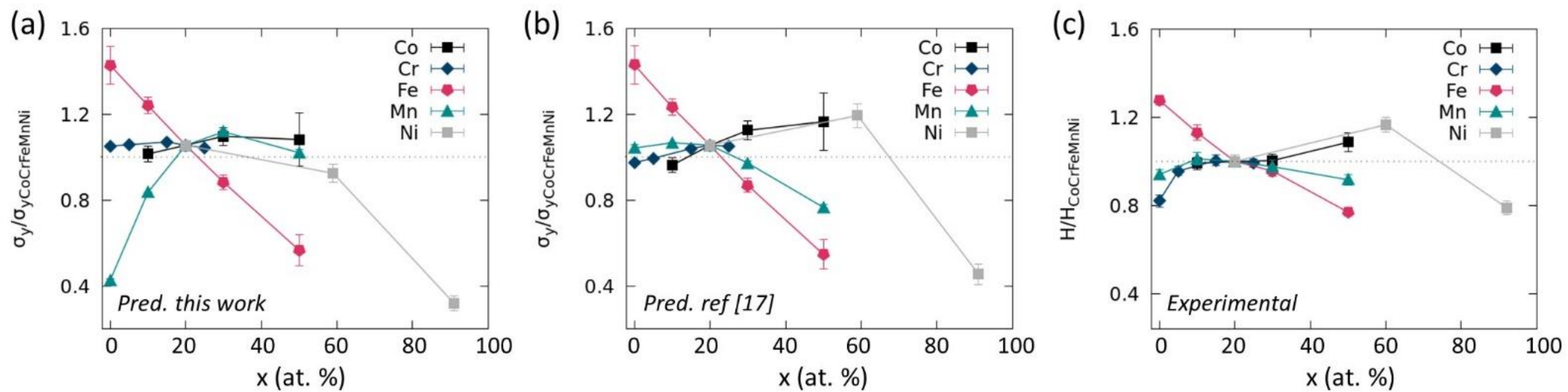

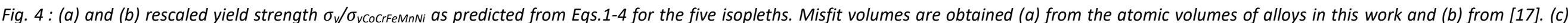

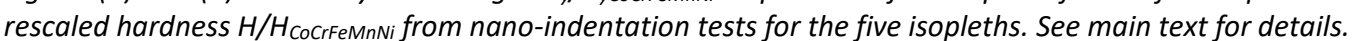



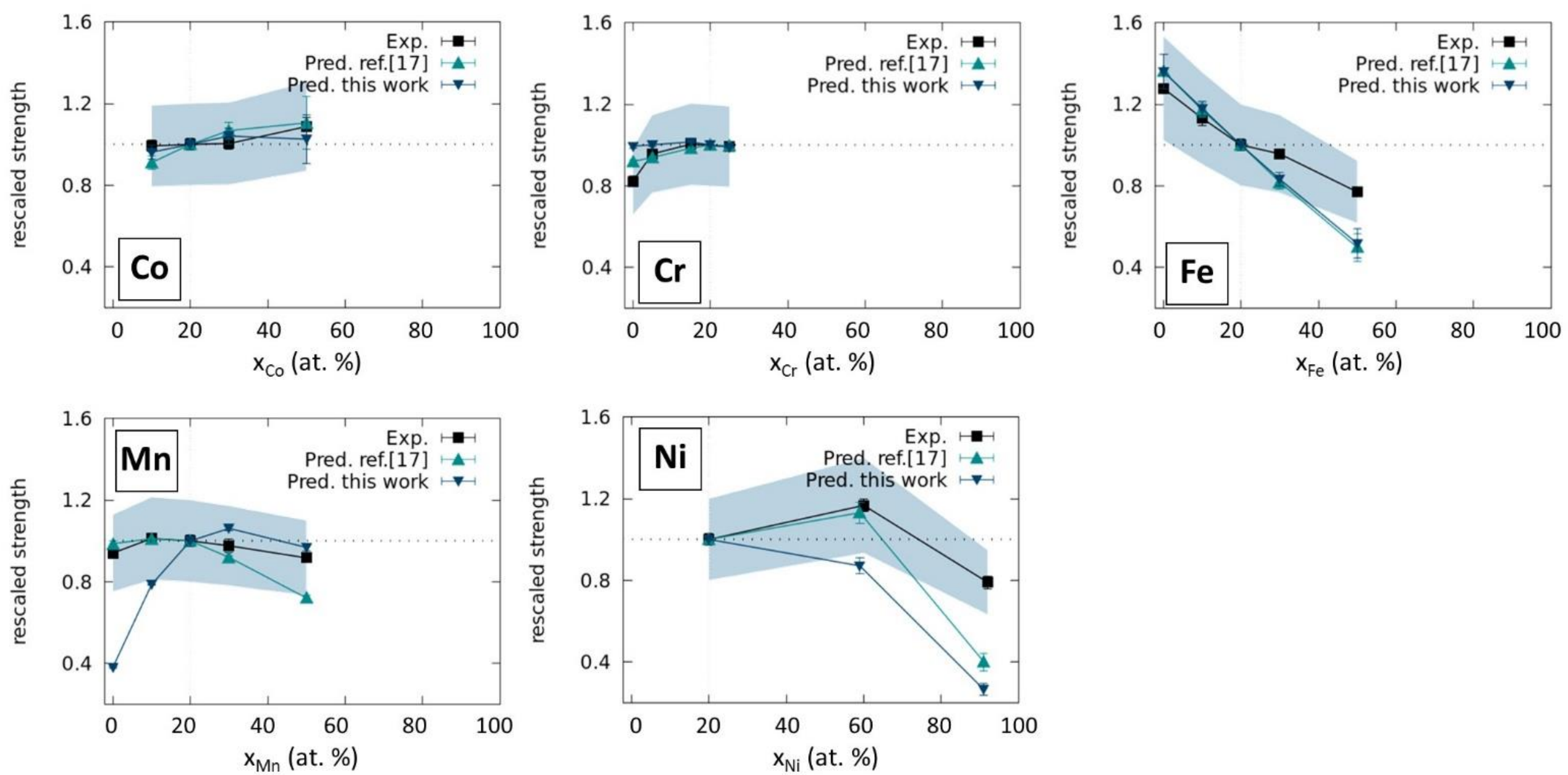

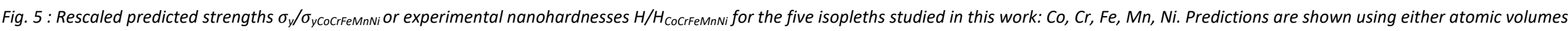

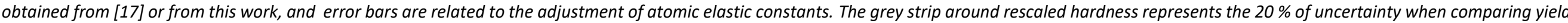
strength and nanohardness. 


\subsection{Experimental strategies for exploring solid solution strengthening of HEAs}

In this work, a specific experimental procedure was used, consisting in: (i) processing small bulk and homogenized samples, (ii) measuring the chemical composition by SEM-EDS and the lattice parameter by $\mathrm{XRD}$, and (iii) measuring the nanohardness by nanoindentation. To do so, first, the processing of alloys is reduced to melting, casting and homogenization annealing. In other words, there is no thermomechanical steps. With this fast procedure a large number of 24 alloy compositions could be studied in this work. Homogenization annealing guarantees the chemical homogeneity and the thermodynamic stability of the studied phases. It also permits to identify compositions for which the fcc phase, although possibly stable at high temperature, cannot be retained at ambient temperature. Having bulk samples, even of sub-centimetric dimensions, allows a precise measurement of the chemical composition and the lattice parameter by standard laboratory characterization techniques (i.e.: SEM-EDS and XRD). Finally, nanoindentation was chosen as an appropriate tool to measure mechanical properties on such small samples. The nanoindentation procedure permits to obtain an average hardness representative of the whole sample and with no strengthening effect of grain boundaries. However, as previously detailed, comparing hardness and yield strength is not straightforward and an uncertainty of $\approx 20 \%$ should be considered in a quantitative approach. Therefore, while nanoindentation on homogenized samples is a powerful tool to probe the mechanical performance of a large set of materials in a systematic way and to identify general trends, care must be taken when trying to correlate the outcome nanohardness values to the intrinsic yield strength, especially when looking at important variations in alloy composition.

Other strategies based on nanoindentation are seen in the literature to probe mechanical properties over compositional space, like the use of diffusion multiples [36,37] and of thin films prepared by combinatorial sputtering [38], which contain undoubtedly a larger number of compositions than in this work. However, the characterization of such samples is more complex and/or less precise. Measuring the lattice parameter requires synchrotron X-ray and is sometimes not performed [36, 37]. Moreover, composition and hardness measurements by SEM-EDS and nanoindentation respectively rely on a single or a few data points. Of course, the limitations which were previously exposed to compare hardness and yield strength still hold. So in general, larger uncertainty is expected from $\mathrm{H}$ values from these approaches. To conclude, the experimental procedure used in this work proposes an original compromise between the need of high-throughput data and precise measurements. It can be ranked in between tensile tests which provide precise mechanical properties but which are very time-consuming and combinatorial processing, such as multiple diffusion and film sputtering, combined with nanoindentation, which explore extremely wide range of compositions and partially measure the properties. All these approaches should be considered as complementary. To do so, the on-going effort to determine limits and uncertainties of each approach should be pursued.

Finally, an even deeper exploration of SSS mechanisms in HEAs should pay attention to the effect of short range ordering (SRO) of chemical species that might exist in SS (see e.g. [39]). In the present work, experimental effort was made to obtain materials representative of the high-temperature states, and the chosen temperature and alloy compositions falls mostly away from transition lines in the phase diagrams. Thus, the presence of SRO was not targeted, and within the experimental precision of the characterization techniques used here, was not detected. Accordingly, the selected model of SSS only considers randomly distributed alloys. It must be noted however that, due to the high number of components, the existence of SRO in the samples cannot be excluded. A specific experimental/modeling investigation of the links between SRO and SSS remains a topic for future work. 


\section{Conclusion}

Twenty-four compositions were selected to cover the domain of the face centered cubic (fcc) solid solutions of the five isopleths from the Co-Cr-Fe-Mn-Ni quinary system and measure mechanical properties. They were processed into an homogeneized state, their lattice parameter and hardness were measured by X-ray diffraction and nanoindentation respectively. Afterwards, the yield strength of these alloys was calculated by a general model for solution strengthening of random fcc alloys. The elemental atomic volumes and elastic constants which are inputs of this model were determined from different datasets, including one from this work. The main conclusions are the following:

- The lattice parameter increases when $\mathrm{Ni}$ and $\mathrm{Mn}$ contents increase and when $\mathrm{Co}$ and Fe contents decrease. This evolution is linear only for $\mathrm{Co}, \mathrm{Fe}$ and $\mathrm{Mn}$. The non-linearity could be related with an evolution of magnetic state.

- There are large variations of hardness with composition. From the 24 studied alloys, the hardest are CoCrMnNi and (CoCrFeMn) ${ }_{40} \mathrm{Ni}_{60}$ whereas the softest are (CoCrFeMn ${ }_{8} \mathrm{Ni}_{92}$ and $(\mathrm{CoCrMnNi})_{50} \mathrm{Fe}_{50}$. The widely studied equimolar CoCrFeMnNi has an intermediate value of hardness.

- The evolution of lattice parameter and hardness with composition is continuous and isoplethspecific. No breakpoint which would be a physical limit between HEA and diluted solid solutions could be identified.

- Nanoindentation on homogeneized samples appears as a powerful tool for high-throughput experimental data collecting, with precise measurements. Still, a significant uncertainty has to be taken into account for comparison with tensile tests and the measurements of elastic constants might not be reliable, depending on the anisotropy of the alloys. A separate technique to obtain the sample elastic constants should be preferred.

- A satisfactory comparison between experimental hardness and modelled yield strength was obtained on the whole for all datasets. Predictions appear to be more sensitive to atomic volume adjustement procedure than to the one of elastic constants.

- The model rationalizes the evolution of solid solution strengthening with composition, which depends on the variations of lattice misfit but also of elastic constants with composition. Noticeably, there is no simple correlation between the evolution of lattice parameter and of lattice misfit.

In the future, this model and the tested datasets should be used to optimize the solid solution strengthening effect and to select new compositions within the Co-Cr-Fe-Mn-Ni class, especially outside the already tested isopleths. The processing, characterization and mechanical testing of these new compositions will provide a first assessment of properties for applications together with additional experimental data to further improve the inputs of the model. Finally, the combined simplified experimental process/modeling approach proposed here will be possible to apply to any fcc HEA system, like the light-weight or noble metals fcc HEAs.

\section{Acknowledgments}

This work benefited from a French government grant managed by ANR within the frame of the national program Investments for the Future ANR-11-LABX-022-01. 


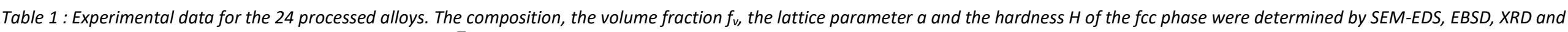

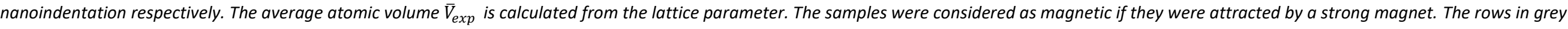
indicate the two-phase samples.

\begin{tabular}{|c|c|c|c|c|c|c|c|c|c|c|c|c|c|c|c|}
\hline \multirow{2}{*}{$\begin{array}{l}\text { Sample } \\
\text { name }\end{array}$} & \multicolumn{5}{|c|}{ Nominal composition (at.\%) } & \multicolumn{5}{|c|}{$\begin{array}{l}\text { Measured composition of the fcc phase } \\
\text { (at. \%) }\end{array}$} & \multirow[t]{2}{*}{$\begin{array}{c}f_{v}(f c c) \\
(\%)\end{array}$} & \multirow[t]{2}{*}{ a $(\AA ̊)$} & \multirow[t]{2}{*}{$\bar{V}_{\text {exp }}\left(\AA^{3}\right)$} & \multirow{2}{*}{$\begin{array}{l}\text { Magnetic } \\
\text { state }\end{array}$} & \multirow[t]{2}{*}{$\mathrm{H}(\mathrm{GPa})$} \\
\hline & Co & $\mathrm{Cr}$ & $\mathrm{Fe}$ & $M n$ & $\mathrm{Ni}$ & Co & $\mathrm{Cr}$ & $\mathrm{Fe}$ & $M n$ & $\mathrm{Ni}$ & & & & & \\
\hline $\mathrm{CoO}$ & 0 & 25 & 25 & 25 & 25 & 0 & 23.8 & 24.9 & 25.8 & 25.5 & 94 & $3.622(2)$ & 11.88 & No & $2.12(.1)$ \\
\hline Co10 & 10 & 22.5 & 22.5 & 22.5 & 22.5 & 10 & 23.1 & 22.5 & 22.5 & 21.9 & 100 & $3.609(2)$ & 11.75 & No & $2.5(.07)$ \\
\hline CoCrFeMnNi & 20 & 20 & 20 & 20 & 20 & 20 & 20.3 & 20 & 20.3 & 19.4 & 100 & $3.601(2)$ & 11.67 & No & $2.52(.07)$ \\
\hline Co30 & 30 & 17.5 & 17.5 & 17.5 & 17.5 & 29.7 & 18.1 & 17.5 & 17.7 & 17 & 100 & $3.593(2)$ & 11.60 & No & $2.53(.07)$ \\
\hline Co50 & 50 & 12.5 & 12.5 & 12.5 & 12.5 & 49.6 & 12.8 & 12.5 & 12.7 & 12.4 & 100 & $3.576(2)$ & 11.43 & No & $2.74(.11)$ \\
\hline Co70 & 70 & 7.5 & 7.5 & 7.5 & 7.5 & 69.4 & 7.7 & 7.7 & 7.7 & 7.5 & 36 & $3.562(2)$ & 11.30 & Yes & - \\
\hline Co90 & 90 & 2.5 & 2.5 & 2.5 & 2.5 & 89.6 & 2.6 & 2.7 & 2.6 & 2.5 & 23 & $3.556(2)$ & 11.24 & Yes & - \\
\hline $\mathrm{CrO}$ & 25 & 0 & 25 & 25 & 25 & 25.1 & 0 & 25 & 25.2 & 24.7 & 100 & $3.603(2)$ & 11.69 & No & $2.07(.07)$ \\
\hline $\mathrm{Cr} 5$ & 23.8 & 5 & 23.8 & 23.8 & 23.8 & 23.7 & 5.2 & 23.9 & 24.2 & 23 & 100 & $3.602(2)$ & 11.68 & No & $2.41(.05)$ \\
\hline Cr15 & 21.3 & 15 & 21.3 & 21.3 & 21.3 & 21.2 & 15.3 & 21.3 & 21.6 & 20.6 & 100 & $3.601(2)$ & 11.67 & No & $2.53(.06)$ \\
\hline Cr25 & 18.8 & 25 & 18.8 & 18.8 & 18.8 & 18.7 & 25.5 & 18.7 & 18.9 & 18.2 & 100 & $3.605(2)$ & 11.71 & No & $2.5(.05)$ \\
\hline $\mathrm{Cr} 42$ & 14.5 & 42 & 14.5 & 14.5 & 14.5 & 15.7 & 30.3 & 15.7 & 17.1 & 21.2 & 31 & $3.609(2)$ & 11.75 & No & - \\
\hline $\mathrm{FeO}$ & 25 & 25 & 0 & 25 & 25 & 24.9 & 25.6 & 0 & 25.1 & 24.4 & 100 & $3.616(2)$ & 11.82 & No & $3.22(.06)$ \\
\hline Fe10 & 22.5 & 22.5 & 10 & 22.5 & 22.5 & 22.3 & 23 & 10 & 22.8 & 21.9 & 100 & $3.609(2)$ & 11.75 & No & $2.85(.09)$ \\
\hline $\mathrm{Fe} 30$ & 17.5 & 17.5 & 30 & 17.5 & 17.5 & 17.4 & 18.1 & 29.8 & 17.7 & 17 & 100 & $3.601(2)$ & 11.67 & No & $2.41(.06)$ \\
\hline Fe50 & 12.5 & 12.5 & 50 & 12.5 & 12.5 & 12.7 & 13 & 49.5 & 12.6 & 12.2 & 100 & $3.593(2)$ & 11.60 & No & $1.94(.05)$ \\
\hline Fe70 & 7.5 & 7.5 & 70 & 7.5 & 7.5 & 8.1 & 10.3 & 64.6 & 6.4 & 10.6 & - & $3.588(2)$ & 11.55 & Yes & - \\
\hline $\mathrm{MnO}$ & 25 & 25 & 25 & 0 & 25 & 24.9 & 25.5 & 25.1 & 0 & 24.5 & 100 & $3.575(2)$ & 11.42 & No & $2.37(.06)$ \\
\hline Mn10 & 22.5 & 22.5 & 22.5 & 10 & 22.5 & 22.4 & 23 & 22.6 & 10.2 & 21.8 & 100 & $3.594(2)$ & 11.61 & No & $2.55(.07)$ \\
\hline Mn30 & 17.5 & 17.5 & 17.5 & 30 & 17.5 & 17.4 & 17.9 & 17.4 & 30.3 & 17 & 100 & $3.616(2)$ & 11.82 & No & $2.46(.08)$ \\
\hline Mn50 & 12.5 & 12.5 & 12.5 & 50 & 12.5 & 12.6 & 12.3 & 12.7 & 50.2 & 12.2 & 100 & $3.644(2)$ & 12.10 & No & $2.31(.06)$ \\
\hline $\mathrm{NiO}$ & 25 & 25 & 25 & 25 & 0 & 26.5 & 22 & 26 & 25.5 & 0 & 65 & $3.596(2)$ & 11.63 & No & - \\
\hline $\mathrm{Ni60}$ & 10 & 10 & 10 & 10 & 60 & 10.4 & 10.5 & 10.4 & 9.6 & 59.1 & 100 & $3.579(2)$ & 11.46 & Yes & $2.94(.08)$ \\
\hline $\mathrm{Ni92}$ & 2 & 2 & 2 & 2 & 92 & 2.1 & 2.1 & 2.2 & 2.4 & 91.2 & 100 & $3.539(2)$ & 11.08 & Yes & $1.99(.06)$ \\
\hline
\end{tabular}

"-" indicates that the property was not possible to measure because of a too small length of the fcc phase domain. 
Table 2 : Elemental elastic constants $\left(\mu_{n}, E_{n}\right)$ are obtained from a linear adjustment on experimental values from Wu et al. [29] and Laplanche et al. [34]. Elemental atomic volumes $V_{n}$ obtained after a linear fitting (Vegard's law) on experimental alloy atomic volumes from this work, or from Varvenne et al. [17]. See main text for details.

\begin{tabular}{|c||c|c|c|c||c|c||}
\hline \multicolumn{1}{|c||}{} & \multicolumn{2}{|c|}{$\mu_{n}$ (GPa) } & \multicolumn{2}{c||}{$E_{n}$ (GPa) } & \multicolumn{2}{c||}{$V_{n}\left(\AA^{3}\right)$} \\
\hline$n$ & Wu et al. & Laplanche et al. & Wu et al. & Laplanche et al. & This work & Varvenne et al. \\
\hline \hline Co & 81.4 & 81.8 & 231.7 & 208.9 & 11.12 & 11.12 \\
\hline Cr & 103.5 & 115.0 & 275.4 & 266.3 & 11.98 & 12.27 \\
\hline Fe & 51.7 & 60.7 & 127.8 & 140.2 & 11.45 & 12.09 \\
\hline Mn & 81.5 & 90.0 & 177.6 & 176.0 & 12.85 & 12.60 \\
\hline Ni & 76.3 & 70.1 & 194.3 & 200.5 & 11.07 & 10.94 \\
\hline
\end{tabular}


Table 3 : Elastic constants $(\bar{\mu}, \bar{v})$, average atomic volume $\bar{V}$ and lattice misfit parameters $\delta$ for the five isopleth single phase alloys, obtained through the linear interpolations of data set from Wu et al. [29], Laplanche et al. [34], Varvenne et al. [17] and from this work. See main text for details.

\begin{tabular}{|c|c|c|c|c|c|c|c|c|}
\hline \multirow[t]{2}{*}{ Sample name } & \multicolumn{2}{|c|}{$\bar{\mu}(\mathrm{GPa})$} & \multicolumn{2}{|r|}{$\bar{v}$} & \multicolumn{2}{|c|}{$\bar{V}\left(\AA^{3}\right)$} & \multicolumn{2}{|c|}{$\delta(\%)$} \\
\hline & Wu & Laplanche & Wu & Laplanche & This work & Varvenne & This work & Varvenne \\
\hline Co10 & 78.9 & 84.1 & 0.253 & 0.178 & 11.78 & 11.90 & 1.90 & 1.81 \\
\hline CoCrFeMnNi & 78.9 & 83.6 & 0.257 & 0.205 & 11.69 & 11.80 & 1.89 & 1.85 \\
\hline Co30 & 79.5 & 83.7 & 0.259 & 0.229 & 11.63 & 11.73 & 1.87 & 1.86 \\
\hline Co50 & 80.1 & 83.3 & 0.265 & 0.281 & 11.49 & 11.56 & 1.74 & 1.78 \\
\hline Cro & 72.7 & 75.7 & 0.247 & 0.208 & 11.62 & 11.69 & 2.07 & 1.95 \\
\hline Cr5 & 74.2 & 77.7 & 0.249 & 0.206 & 11.65 & 11.72 & 2.03 & 1.93 \\
\hline Cr15 & 77.4 & 81.7 & 0.253 & 0.203 & 11.68 & 11.78 & 1.95 & 1.88 \\
\hline Cr25 & 80.4 & 85.6 & 0.259 & 0.203 & 11.72 & 11.84 & 1.84 & 1.81 \\
\hline $\mathrm{FeO}$ & 86.0 & 89.7 & 0.242 & 0.229 & 11.76 & 11.75 & 2.06 & 2.02 \\
\hline Fe10 & 82.4 & 86.7 & 0.248 & 0.215 & 11.74 & 11.78 & 1.98 & 1.94 \\
\hline Fe30 & 75.6 & 81.0 & 0.265 & 0.187 & 11.68 & 11.85 & 1.79 & 1.74 \\
\hline Fe50 & 68.8 & 75.3 & 0.284 & 0.155 & 11.62 & 11.93 & 1.55 & 1.49 \\
\hline Mno & 78.5 & 82.4 & 0.303 & 0.263 & 11.41 & 11.62 & 1.07 & 1.67 \\
\hline Mn10 & 78.6 & 82.9 & 0.280 & 0.232 & 11.56 & 11.72 & 1.59 & 1.78 \\
\hline Mn30 & 79.2 & 84.5 & 0.235 & 0.173 & 11.84 & 11.92 & 2.04 & 1.85 \\
\hline Mn50 & 79.6 & 85.8 & 0.189 & 0.119 & 12.13 & 12.10 & 2.11 & 1.77 \\
\hline Ni60 & 77.9 & 77.3 & 0.285 & 0.285 & 11.39 & 11.39 & 1.65 & 1.87 \\
\hline Ni92 & 76.6 & 71.6 & 0.307 & 0.361 & 11.14 & 11.04 & 0.91 & 1.07 \\
\hline
\end{tabular}




\section{Appendix}

Contrary to most of the studied alloys, $\mathrm{Co}, \mathrm{Cr} 42, \mathrm{Co} 70, \mathrm{Co90}, \mathrm{NiO}$ and $\mathrm{Fe} 70$ are multi-phase. Thus they were additionally characterized by ElectronBackScattered Diffraction (EBSD), except for Fe70, for which the phases were too small to be clearly identified by this technique (Fig. A 1).

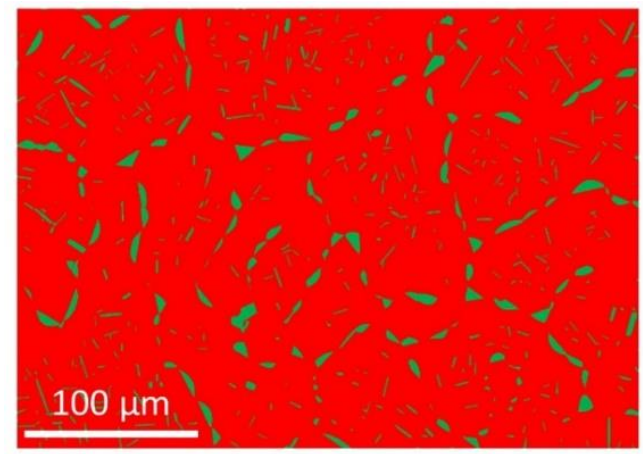

(a) $\mathrm{CoO}$

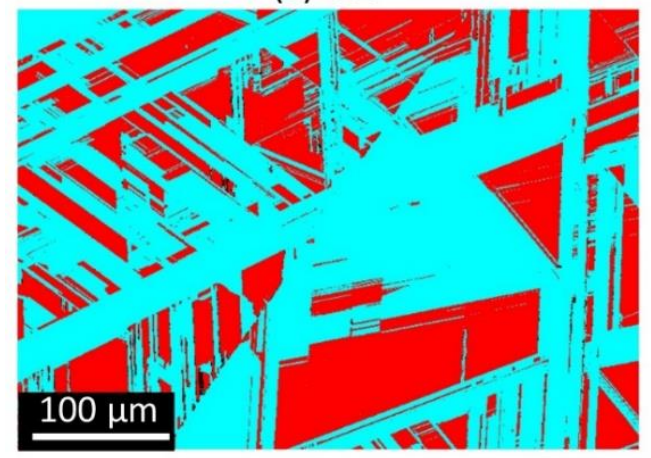

(c) $\mathrm{Co70}$

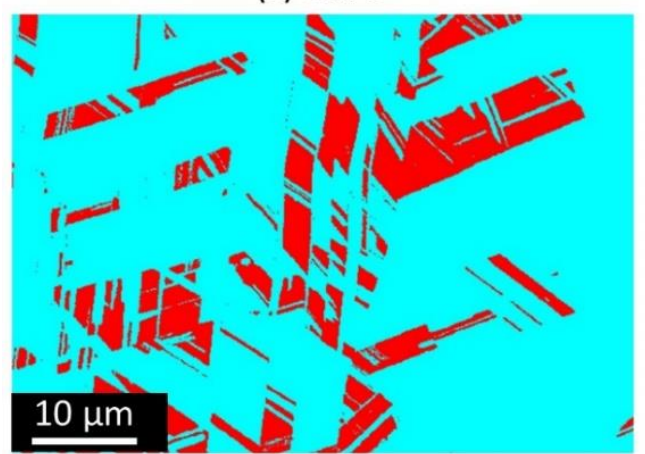

(e) $\operatorname{Cog} 0$

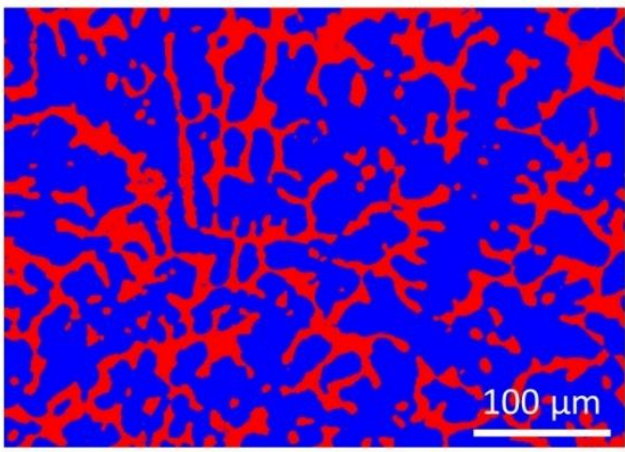

(b) $\mathrm{Cr} 42$

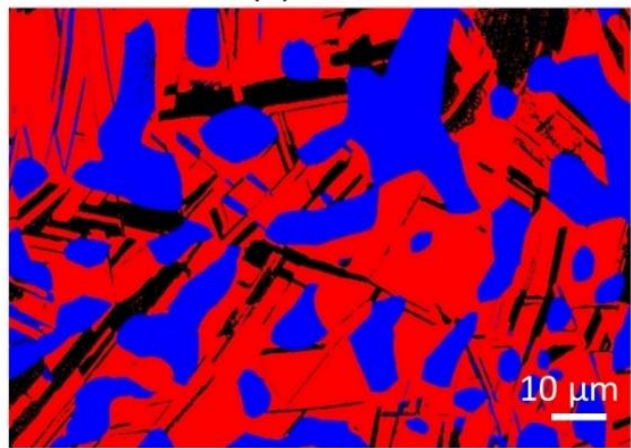

(d) $\mathrm{NiO}$

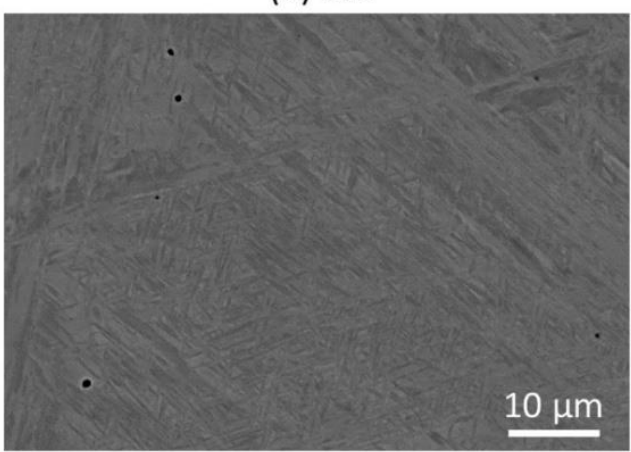

(f) Fe70

\begin{tabular}{|llllll|}
\hline $\mathrm{fcc}$ & $\mathrm{bcc}$ & $\sigma$ & $\mathrm{Co}$ & $\mathbf{0}$ & Un-indexed \\
\hline
\end{tabular}

Fig. A 1 : (a-e) EBSD maps of phases of two-phase processed alloys. (f) BSE-SEM image of the two-phase alloy Fe70 
The experimental elastic constants which were used to determined two sets of atomic elastic constants $\mu_{n}$ and $v_{n}$ are listed in Table A1. The absolute values of yield strength which were calculated using these sets of elastic constants combined with two other sets of atomic volumes $V_{n}$ are given in Table A2.

Table A1 : Elastic constants $(\mu, v)$ at room temperature for various equiatomic multicomponent fcc solid solutions within the Co-Cr-FeMn-Ni family of alloys, from Wu et al. [29] and Laplanche et al. [34].

\begin{tabular}{|c|c|c|c|c|c|c|c|}
\hline $\mathrm{c}_{\mathrm{co}}$ & $c_{c r}$ & $\mathrm{C}_{\mathrm{Fe}}$ & $c_{M n}$ & $\mathrm{C}_{\mathrm{Ni}}$ & $\mu(\mathrm{GPa})$ & $v$ & Ref. \\
\hline 0.49 & 0.00 & 0.00 & 0.00 & 0.51 & 76 & 0.43 & [34] \\
\hline 0.32 & 0.00 & 0.34 & 0.00 & 0.33 & 68 & 0.28 & [34] \\
\hline 0.33 & 0.33 & 0.00 & 0.00 & 0.33 & 90 & 0.31 & [34] \\
\hline 0.33 & 0.00 & 0.00 & 0.35 & 0.32 & 79 & 0.20 & [34] \\
\hline 0.00 & 0.00 & 0.34 & 0.33 & 0.33 & 77 & 0.15 & [34] \\
\hline 0.00 & 0.34 & 0.32 & 0.00 & 0.34 & 79 & 0.20 & [34] \\
\hline 0.25 & 0.24 & 0.25 & 0.01 & 0.25 & 86 & 0.25 & [34] \\
\hline 0.20 & 0.20 & 0.20 & 0.20 & 0.20 & 81 & 0.25 & [34] \\
\hline 0.00 & 0.00 & 0.00 & 0.00 & 1.00 & 76 & 0.31 & [29] \\
\hline 0.50 & 0.00 & 0.00 & 0.00 & 0.50 & 84 & 0.29 & [29] \\
\hline 0.00 & 0.00 & 0.50 & 0.00 & 0.50 & 62 & 0.34 & [29] \\
\hline 0.33 & 0.00 & 0.33 & 0.00 & 0.33 & 60 & 0.35 & [29] \\
\hline 0.33 & 0.33 & 0.00 & 0.00 & 0.33 & 87 & 0.30 & [29] \\
\hline 0.33 & 0.00 & 0.00 & 0.33 & 0.33 & 77 & 0.23 & [29] \\
\hline 0.00 & 0.00 & 0.33 & 0.33 & 0.33 & 73 & 0.24 & [29] \\
\hline 0.25 & 0.25 & 0.25 & 0.00 & 0.25 & 84 & 0.28 & [29] \\
\hline 0.25 & 0.00 & 0.25 & 0.25 & 0.25 & 77 & 0.22 & [29] \\
\hline 0.25 & 0.25 & 0.00 & 0.25 & 0.25 & 78 & 0.25 & [29] \\
\hline 0.20 & 0.20 & 0.20 & 0.20 & 0.20 & 80 & 0.26 & [29] \\
\hline
\end{tabular}


Table A2 : Predicted yield strengths $\sigma_{y}$ calculated by combining the sets of atomic volume $V_{n}$ (from this work or from Varvenne et al. [17]) with the sets of elastic constants from from Wu et al. [29] and Laplanche et al. [34].

\begin{tabular}{|c|c|c|c|c|}
\hline \multirow[b]{3}{*}{ Sample name } & \multicolumn{4}{|c|}{$\sigma_{y}\left(T=300 K, \dot{\epsilon}=10^{3} \cdot s^{-1}\right)(\mathrm{MPa})$} \\
\hline & \multicolumn{2}{|c|}{$V_{n}$ from this work } & \multicolumn{2}{|c|}{$V_{n}$ from Varvenne et al. [17] } \\
\hline & Wu & Laplanche & Wu & Laplanche \\
\hline Co10 & 112 & 94 & 103 & 86 \\
\hline CoCrFeMnNi & 113 & 102 & 109 & 98 \\
\hline Co30 & 113 & 110 & 112 & 109 \\
\hline Co50 & 102 & 116 & 107 & 121 \\
\hline $\mathrm{CrO}$ & 111 & 102 & 99 & 91 \\
\hline Cr5 & 112 & 102 & 102 & 93 \\
\hline Cr15 & 114 & 103 & 107 & 97 \\
\hline Cr25 & 112 & 100 & 109 & 98 \\
\hline $\mathrm{Fe} 0$ & 144 & 147 & 139 & 142 \\
\hline Fe10 & 129 & 124 & 124 & 119 \\
\hline Fe30 & 97 & 81 & 93 & 77 \\
\hline Fe50 & 66 & 45 & 62 & 42 \\
\hline Mno & 42 & 39 & 106 & 98 \\
\hline Mn10 & 88 & 80 & 110 & 100 \\
\hline Mn30 & 121 & 107 & 101 & 90 \\
\hline Mn50 & 111 & 97 & 80 & 70 \\
\hline Ni60 & 94 & 92 & 118 & 116 \\
\hline $\mathrm{Ni92}$ & 26 & 30 & 39 & 44 \\
\hline
\end{tabular}




\section{References}

[1] B. Cantor, I.T.H. Chang, P. Knight, A.J.B. Vincent, Microstructural development in equiatomic multicomponent alloys, Materials Science and Engineering: A 375-377 (2004) 213-218.

[2] M. Laurent-Brocq, A. Akhatova, L. Perrière, S. Chebini, X. Sauvage, E. Leroy, Y. Champion, Insights into the phase diagram of the CrMnFeCoNi high entropy alloy, Acta Mater. 88(0) (2015) 355-365.

[3] J.W. Yeh, S.K. Chen, S.J. Lin, J.Y. Gan, T.S. Chin, T.T. Shun, C.H. Tsau, S.Y. Chang, Nanostructured highentropy alloys with multiple principal elements: Novel alloy design concepts and outcomes, Advanced Engineering Materials 6(5) (2004) 299-303.

[4] B. Gludovatz, A. Hohenwarter, D. Catoor, E.H. Chang, E.P. George, R.O. Ritchie, A fracture-resistant highentropy alloy for cryogenic applications, Science 345(6201) (2014) 1153-1158.

[5] G. Laplanche, A. Kostka, O.M. Horst, G. Eggeler, E.P. George, Microstructure evolution and critical stress for twinning in the CrMnFeCoNi high-entropy alloy, Acta Mater. 118 (2016) 152-163.

[6] F. Otto, A. Dlouhý, C. Somsen, H. Bei, G. Eggeler, E.P. George, The influences of temperature and microstructure on the tensile properties of a CoCrFeMnNi high-entropy alloy, Acta Mater. 61(15) (2013) 5743-5755.

[7] N.D. Stepanov, D.G. Shaysultanov, M.A. Tikhonovsky, G.A. Salishchev, Tensile properties of the $\mathrm{Cr}-\mathrm{Fe}-\mathrm{Ni}-$ Mn non-equiatomic multicomponent alloys with different Cr contents, Materials \& Design 87 (2015) 60-65.

[8] Z. Wu, H. Bei, Microstructures and mechanical properties of compositionally complex Co-free FeNiMnCr18 FCC solid solution alloy, Materials Science and Engineering a-Structural Materials Properties Microstructure and Processing 640 (2015) 217-224.

[9] M.J. Yao, K.G. Pradeep, C.C. Tasan, D. Raabe, A novel, single phase, non-equiatomic FeMnNiCoCr highentropy alloy with exceptional phase stability and tensile ductility, Scr. Mater. 72-73(0) (2014) 5-8.

[10] B. Gludovatz, A. Hohenwarter, K.V.S. Thurston, H. Bei, Z. Wu, E.P. George, R.O. Ritchie, Exceptional damage-tolerance of a medium-entropy alloy $\mathrm{CrCoNi}$ at cryogenic temperatures, Nature Communication 7 (2016).

[11] G. Laplanche, A. Kostka, C. Reinhart, J. Hunfeld, G. Eggeler, E.P. George, Reasons for the superior mechanical properties of medium-entropy $\mathrm{CrCoNi}$ compared to high-entropy CrMnFeCoNi, Acta Mater. 128 (2017) 292-303.

[12] K.G. Pradeep, C.C. Tasan, M.J. Yao, Y. Deng, H. Springer, D. Raabe, Non-equiatomic high entropy alloys: Approach towards rapid alloy screening and property-oriented design, Materials Science and Engineering: A 648 (2015) 183-192.

[13] G. Bracq, M. Laurent-Brocq, L. Perrière, R. Pirès, J.-M. Joubert, I. Guillot, The fcc solid solution stability in the Co-Cr-Fe-Mn-Ni multi-component system, Acta Mater. 128 (2017) 327-336.

[14] T. Rieger, M. Laurent-Brocq, L. Perrière, I. Guillot, J.-M. Joubert, J.-P. Couzinié, Massive Calphad calculations for the development of high entropy alloys strengthened by L12 precipitates, (Submitted).

[15] J.Y. He, H. Wang, H.L. Huang, X.D. Xu, M.W. Chen, Y. Wu, X.J. Liu, T.G. Nieh, K. An, Z.P. Lu, A precipitationhardened high-entropy alloy with outstanding tensile properties, Acta Mater. 102 (2016) 187-196.

[16] Y.-J. Liang, L. Wang, Y. Wen, B. Cheng, Q. Wu, T. Cao, Q. Xiao, Y. Xue, G. Sha, Y. Wang, Y. Ren, X. Li, L. Wang, F. Wang, H. Cai, High-content ductile coherent nanoprecipitates achieve ultrastrong high-entropy alloys, Nature Communications 9(1) (2018) 4063.

[17] C. Varvenne, A. Luque, W.A. Curtin, Theory of strengthening in fcc high entropy alloys, Acta Mater. 118 (2016) 164-176.

[18] M. Laurent-Brocq, L. Perrière, R. Pirès, Y. Champion, From high entropy alloys to diluted multicomponent alloys: Range of existence of a solid-solution, Materials \& Design 103 (2016) 84-89.

[19] M. Laurent-Brocq, L. Perrière, R. Pirès, F. Prima, P. Vermaut, Y. Champion, From diluted solid solutions to high entropy alloys: On the evolution of properties with composition of multi-components alloys, Materials Science and Engineering: A 696 (2017) 228-235. 
[20] J. Rodríguez-Carvajal, Fullprof: a program for rietveld refinement and pattern matching analysis, Satellite Meeting on Powder Diffraction of the XV Congress of the IUCr, Toulouse, France, 1990, p. 13.

[21] M. Laurent-Brocq, L. Perrière, R. Pirès, G. Bracq, T. Rieger, Y. Danard, I. Guillot, Tensile properties of multi-components alloys: from HEA to diluted solid solutions, (Submitted).

[22] M. Laurent-Brocq, E. Béjanin, Y. Champion, Influence of roughness and tilt on nanoindentation measurements: A quantitative model, Scanning 9999 (2015) 1-11.

[23] W.C. Oliver, G.M. Pharr, An improved technique for determining hardness and elastic modulus using load and displacement sensing indentation experiments, J. Mater. Res. 7(06) (1992) 1564-1583.

[24] X. Li, B. Bhushan, A review of nanoindentation continuous stiffness measurement technique and its applications, Mater. Charact. 48(1) (2002) 11-36.

[25] W.D. Nix, H. Gao, Indentation size effects in crystalline materials: A law for strain gradient plasticity, J. Mech. Phys. Solids 46(3) (1998) 411-425.

[26] E. Clouet, S. Garruchet, H. Nguyen, M. Perez, C.S. Becquart, Dislocation interaction with C in alpha-Fe: A comparison between atomic simulations and elasticity theory, Acta Mater. 56(14) (2008) 3450-3460.

[27] C. Varvenne, W.A. Curtin, Strengthening of high entropy alloys by dilute solute additions: CoCrFeNiAlx and CoCrFeNiMnAlx alloys, Scr. Mater. 138 (2017) 92-95.

[28] G. Laplanche, P. Gadaud, O. Horst, F. Otto, G. Eggeler, E.P. George, Temperature dependencies of the elastic moduli and thermal expansion coefficient of an equiatomic, single-phase CoCrFeMnNi high-entropy alloy, J. Alloys Compd. 623 (2015) 348-353.

[29] Z. Wu, Y. Gao, H. Bei, Thermal activation mechanisms and Labusch-type strengthening analysis for a family of high-entropy and equiatomic solid-solution alloys, Acta Mater. 120 (2016) 108-119.

[30] A.J. Zaddach, C. Niu, C.C. Koch, D.L. Irving, Mechanical Properties and Stacking Fault Energies of NiFeCrCoMn High-Entropy Alloy, JOM 65(12) (2013) 1780-1789.

[31] B. Yang, H. Vehoff, Dependence of nanohardness upon indentation size and grain size - A local examination of the interaction between dislocations and grain boundaries, Acta Mater. 55(3) (2007) 849856.

[32] Z. Wu, H. Bei, G.M. Pharr, E.P. George, Temperature dependence of the mechanical properties of equiatomic solid solution alloys with face-centered cubic crystal structures, Acta Mater. 81(0) (2014) 428441.

[33] H. Zhang, X. Sun, S. Lu, Z. Dong, X. Ding, Y. Wang, L. Vitos, Elastic properties of AlxCrMnFeCoNi $(0 \leq x \leq$ 5) high-entropy alloys from ab initio theory, Acta Mater. 155 (2018) 12-22.

[34] G. Laplanche, P. Gadaud, C. Bärsch, K. Demtröder, C. Reinhart, J. Schreuer, E.P. George, Elastic moduli and thermal expansion coefficients of medium-entropy subsystems of the CrMnFeCoNi high-entropy alloy, J. Alloys Compd. 746 (2018) 244-255.

[35] C. Varvenne, W.A. Curtin, Predicting yield strengths of noble metal high entropy alloys, Scr. Mater. 142 (2018) 92-95.

[36] F.G. Coury, P. Wilson, K.D. Clarke, M.J. Kaufman, A.J. Clarke, High-throughput solid solution strengthening characterization in high entropy alloys, Acta Mater. 167 (2019) 1-11.

[37] P. Wilson, R. Field, M. Kaufman, The use of diffusion multiples to examine the compositional dependence of phase stability and hardness of the Co-Cr-Fe-Mn-Ni high entropy alloy system, Intermetallics 75 (2016) 1524.

[38] S.A. Kube, S. Sohn, D. Uhl, A. Datye, A. Mehta, J. Schroers, Phase selection motifs in High Entropy Alloys revealed through combinatorial methods: Large atomic size difference favors BCC over FCC, Acta Mater. 166 (2019) 677-686.

[39] C. Niu, A.J. Zaddach, A.A. Oni, X. Sang, J.W. Hurt, J.M. LeBeau, C.C. Koch, D.L. Irving, Spin-driven ordering of $\mathrm{Cr}$ in the equiatomic high entropy alloy NiFeCrCo, Appl. Phys. Lett. 106(16) (2015) 161906. 